\title{
Phosphotyrosine recognition domains: the typical, the atypical and the versatile
}

Tomonori Kaneko ${ }^{1 \dagger}$, Rakesh Joshi ${ }^{1 \dagger}$, Stephan M Feller ${ }^{2}$ and Shawn SC $\mathrm{Li}^{{ }^{*}}$

\begin{abstract}
SH2 domains are long known prominent players in the field of phosphotyrosine recognition within signaling protein networks. However, over the years they have been joined by an increasing number of other protein domain families that can, at least with some of their members, also recognise pTyr residues in a sequence-specific context. This superfamily of pTyr recognition modules, which includes substantial fractions of the PTB domains, as well as much smaller, or even single member fractions like the HYB domain, the PKC $\delta$ and PKCO C2 domains and RKIP, represents a fascinating, medically relevant and hence intensely studied part of the cellular signaling architecture of metazoans. Protein tyrosine phosphorylation clearly serves a plethora of functions and pTyr recognition domains are used in a similarly wide range of interaction modes, which encompass, for example, partner protein switching, tandem recognition functionalities and the interaction with catalytically active protein domains. If looked upon closely enough, virtually no pTyr recognition and regulation event is an exact mirror image of another one in the same cell. Thus, the more we learn about the biology and ultrastructural details of pTyr recognition domains, the more does it become apparent that nature cleverly combines and varies a few basic principles to generate a sheer endless number of sophisticated and highly effective recognition/regulation events that are, under normal conditions, elegantly orchestrated in time and space. This knowledge is also valuable when exploring pTyr reader domains as diagnostic tools, drug targets or therapeutic reagents to combat human diseases.
\end{abstract}

Keywords: Posttranslational modification, Phosphotyrosine signaling, Ligand recognition specificity, Cancer therapeutics, Signaling circuit

\section{Background}

\section{Phosphotyrosine signaling}

Intracellular communication is transmitted via networks of molecules that execute information transfer using protein-mediated interactions. Post-translational modifications (PTMs) such as protein phosphorylation, acetylation, methylation and ubiquitination confer spatiotemporal dynamics to cell signaling [1]. Among these PTMs, the tyrosine phosphorylation signaling system in eukaryotes, especially in mammalian species, has been extensively studied owing to its importance in numerous cellular functions including differentiation, proliferation, motility and apoptosis as well as its therapeutic potential. In

\footnotetext{
* Correspondence: sli@uwo.ca

${ }^{\dagger}$ Equal contributors

'Department of Biochemistry and the Siebens-Drake Medical Research Institute, Schulich School of Medicine and Dentistry, University of Western Ontario, London, Ontario N6A 5C1, Canada

Full list of author information is available at the end of the article
}

particular, mutations and aberrant expression of kinases are frequently associated with tumourigenesis $[2,3]$.

Signaling proteins often possess a cassette-like architecture made up of catalytic domains and/or protein interaction modules [4]. One important group of protein-protein interaction modules are the autonomous domains that recognize phosphorylated tyrosine (pTyr) residues at specific sites on their target molecules [5]. These pTyr-binding protein modules and their targets are a part of an elaborate pTyr signaling system that consists of three major components that help relay molecular messages [6]. The pTyr signaling system is activated when a stimulus reaches catalytic proteins that act as "writers" of phosphorylation, the protein tyrosine kinases (PTKs). Most PTKs are phosphorylated on themselves to attain an active state, and subsequently phosphorylate other substrate proteins. A second group of proteins that contain modular domains are capable

\section{() Biomed Central}


of recognizing or "reading" this phospho-modification information and thereby linking the kinase signal to downstream molecules. The phosphorylation can be subsequently "erased" by a third group of proteins, the protein tyrosine phosphatases (PTPs), therefore terminating the signal $[7,8]$.

The human genome harbours 90 PTKs [9], hundreds of pTyr-recognition domains that include 121 members of the Src homology 2 (SH2) domain family [10-12], and more than 10,000 tyrosine phosphorylation sites $[12,13]$. These signaling components form an enormous network of pTyr signaling that is both robust and dynamic. Nature is equipped with multiple strategies to reduce possible misfiring of pTyr signals due to the complexity of pTyr signaling network. First, PTKs can remain inactive until they are stimulated by a proper cue, most typically by association of a specific ligand molecule to the PTK. For example, receptor tyrosine kinases (RTKs), transmembrane proteins consisting of an extracellular ligand binding site and an intracellular tyrosine kinase domain, are designed inactive until a ligand binds to the extracellular site of the RTK, which often induces RTK oligomerization [14]. Structural studies have also revealed the presence of both active and inactive conformations for many cytoplasmic and receptor kinases $[15,16]$. Moreover, the level of PTP activity is very high in cells, thereby ensuring that pTyr sites can be rapidly dephosphorylated [17].

Second, each component of the pTyr signaling circuit, i.e., a PTK, PTP or pTyr-binding module, possesses substrate or ligand recognition specificity to narrow down potential interaction partners [18-23]. Since all three components are the modules that bind to linear motif peptides, the specificity at the molecular or atomic level is defined by the ligand peptide sequence and can also be contributed by conformation of the peptide. The interaction specificity is further enhanced by spatiotemporal regulation of the network components, including tissue-specific or cell cycledependent protein expression, protein localization to subcellular compartments or a scaffold protein, and protein inactivation involving receptor internalization (endocytosis) and/or protein degradation. These multiple layers of regulatory mechanisms are essential for coordinating such a complex functional network $[1,15,24,25]$. However, an unintended activation of pTyr signaling, or misfiring, may occur when a circuit component malfunctions, most commonly due to mutations, overexpression or loss of a component or an element, as we will discuss some cases below.

This review will focus on the pTyr "reader" proteins contributing to this complex system. In addition to the $\mathrm{SH} 2$ and phosphotyrosine-binding (PTB) domains, the two archetype domain families known for pTyr binding, recent studies have shown that at least a handful of additional protein modules are capable of reading out the tyrosine phosphorylation. Here we review and explore the structure, function, specificity and therapeutic potentials of a number of typical and atypical members of the superfamily of pTyr-binding protein modules.

\section{The $\mathrm{SH} 2$ domain}

The Src homology 2 (SH2) domains, a non-catalytic module containing $\sim 100$ amino acids, was first discovered by insertion-mutation analysis of the $v$-fps/fes oncogene from the Fujinami sarcoma virus [26] (for historical perspectives of tyrosine phosphorylation studies, refer to reviews by Pawson [27] and Hunter [3]). Soon thereafter, the $\mathrm{SH} 2$ domain was identified in oncogenes such as $v$-crk and in the endogenous cytoplasmic proteins phospholipase $\mathrm{C} \gamma 1$ (PLC $\gamma 1$ ) and the Ras GTPase activating protein (RasGAP) [28,29]. SH2 domains have since been identified in a wide range of eukaryotic species, including yeast, but primarily in metazoans $[7,11]$. A recent tally finds $121 \mathrm{SH} 2$ in 111 proteins in the human genome [11]. Proteins containing SH2 domains include those that function as kinases, adaptors, phosphatases, ubiquitin ligases, transcription factors, guanine nucleotide exchange factors and phospholipid-based secondary signaling molecules $[5,12,30]$. Studies in almost two decades have demonstrated the tyrosine phosphorylation-dependent nature of typical $\mathrm{SH} 2$ domain-ligand interactions [31-34], the central role played by $\mathrm{SH} 2$ domains in connecting activated receptor tyrosine kinases, such as the epithelial growth factor receptor (EGFR) and the platelet-derived growth factor receptor (PDGFR), to cytoplasmic signaling molecules [29,35]. In addition, kinase $\mathrm{SH} 2$ domains are essential in regulating the catalytic activity of cytoplasmic kinases as exemplified for the Src family as well as the Fes and Abl kinases [15]. A growing picture illustrates that kinase $\mathrm{SH} 2$ domains may regulate catalytic activity utilizing diverse mechanisms $[16,36]$. These and other lines of work establish the $\mathrm{SH} 2$ domain as a key player in the cellular signaling system in a pTyr-dependent manner [37].

\section{Architecture of the SH2 domain}

As represented by the $\mathrm{v}-\mathrm{Src} \mathrm{SH} 2$ domain (Figure 1A), the structure of an $\mathrm{SH} 2$ domain features two $\alpha$-helices $(\alpha \mathrm{A}$ and $\alpha \mathrm{B})$ sandwiching a $\beta$-sheet consisting of seven anti-parallel strands ( $\beta A-\beta G)[38,39]$. Based on the experimentally determined structures of $\sim 70$ unique $\mathrm{SH} 2$ domains in the Protein Data Bank (PDB), the Nterminal region of the $\mathrm{SH} 2$ domain that provides a pTyr-binding pocket is more conserved than the Cterminal half of the $\mathrm{SH} 2$ domain that exhibits greater structural variability (Figure 1B). For instance, sequence 
A

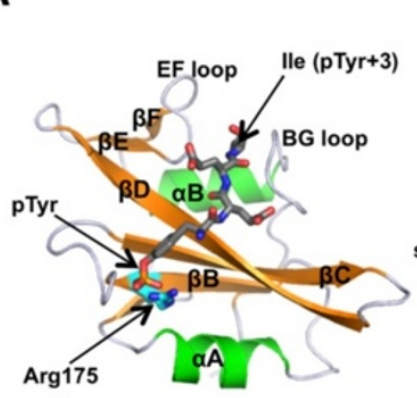

C

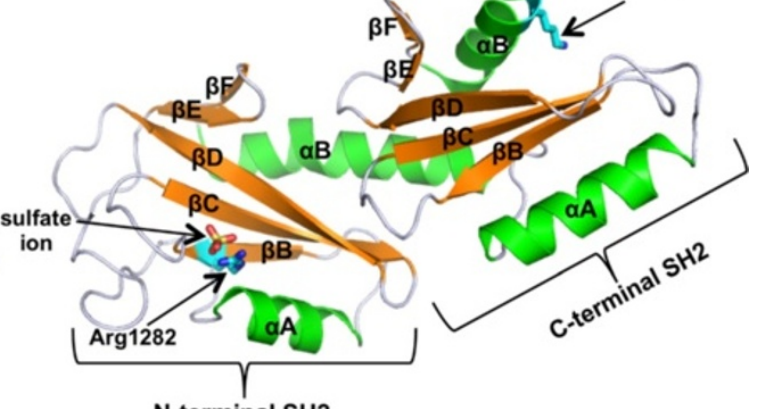

$\mathrm{N}$-terminal SH2

B

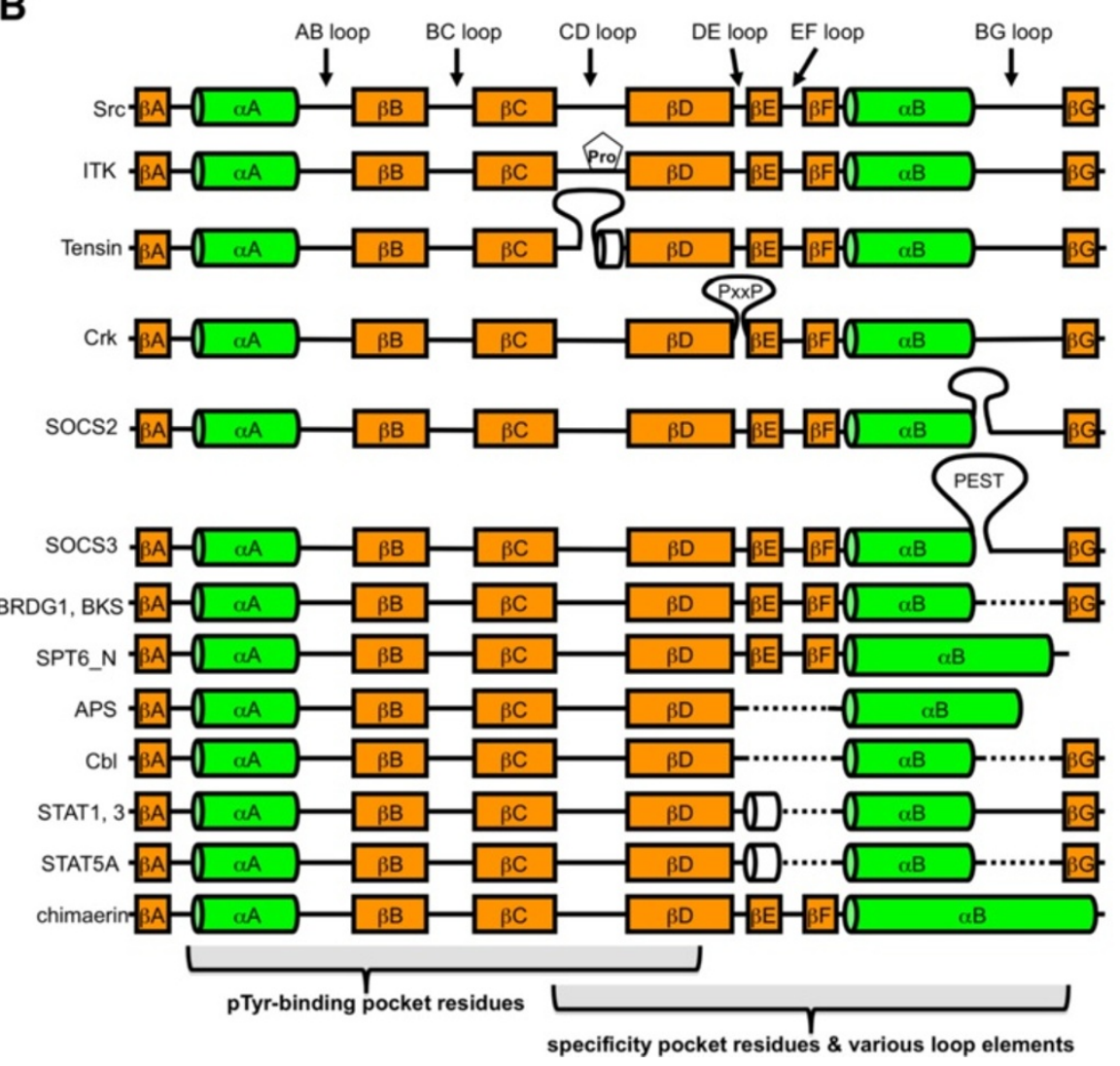

Figure 1 Structure and sequence patterns of the SH2 domain. (A) Structure of the $v$-Src SH2 domain in complex with the pYEEI peptide (PDB ID: 1SPS). The two conserved a-helices are coloured green, and the seven $\beta$-strands are coloured orange. The peptide is shown as grey sticks. The phosphate group of pTyr binds to Arg175 located on the $\beta B$ strand of the SH2 domain. The pTyr+3 lle side chain is captured by a hydrophobic pocket provided between the EF and BG loops. (B) Conservation and variation in the secondary structural elements of SH2 domains based on experimentally determined structures. Refer to [40] for a list of SH2 domain structures. The N-terminal half of an SH2 domain is dedicated to pTyr recognition and is much less variable than the C-terminal half where the specificity pocket is located. A dashed line indicates that the element does not exist in an SH2 domain. Structural variations are observed more often in the C-terminal half. For example, the BG loop of the STAP family (BRDG1 \& BKS) and the Cbl family SH2 domains are much shorter than in other SH2 domains, which results in an open pocket capable of binding a hydrophobic pTyr +4 residue $[40,43]$. Pro287 of the ITK SH2 domain is susceptible to cis-trans isomerization via its CD loop, which leads to a switch of binding partners [44-46]. The long, proline-rich DE loop insertion in the Crk SH2 domain is the binding site for the Abl SH3 domain [47]. (C) The tandem SH2 domains of the transcription factor Spt6. Four research groups have reported crystal and solution structures, which are essentially identical to each other [48-51]. Shown here is the crystal structure of the Saccharomyces cerevisiae Spt6 with a sulfate ion located in the "canonical" phospho-residue binding pocket of the N-terminal SH2 domain (PDB ID: 3PSK) [48]. Mutagenesis studies and NMR titration analysis suggested that this pocket, involving Arg1282, as well as a positively charged patch, including Lys 1435 of the C-terminal SH2 domain (residues shown as cyan sticks), are the binding sites of the phosphorylated CTD peptides [49,50,52]. 
deletion or insertion is found primarily in the $\beta E-\beta F$ and BG loop regions (Figure 1B). In addition, structurebased sequence alignment revealed that the most conserved residues are clustered on the $\beta B$ strand [40]. For the majority of experimentally solved SH2-ligand complex structures, the bound pTyr-peptide forms an extended conformation and binds perpendicular to the central $\beta$-strands of the SH2 domain (Figure 1A). Specific residues in the $\mathrm{N}$-terminal region $(\alpha \mathrm{A}$ to $\beta \mathrm{D})$ form a positively charged pocket for binding of the $\mathrm{pTyr}$ residue $[38,39,41]$. A conserved arginine residue on the strand $\beta B($ Arg175 in the v-Src SH2 domain) (Figure 1A) plays the central role in forming bi-dentate hydrogen bonds with the phosphate moiety of pTyr. In contrast, a hydrophobic pocket provided by the second half of the domain (i.e. $\beta D$ to $\beta G$ ) engages residues $C$-terminal to the $\mathrm{pTyr}$ of a ligand peptide to confer specificity $[12,30,42]$.

\section{Specificity of the $\mathrm{SH} 2$ domain}

$\mathrm{SH} 2$ domains are equipped for the specific recognition of a subset of pTyr-containing ligands [20,22,53-55]. A number of studies have established that binding affinity of an $\mathrm{SH} 2$ domain to a pTyr-containing ligand is moderate, with the typical affinity range between $0.1 \mu \mathrm{M}$ and $10 \mu \mathrm{M}$ for equilibrium dissociation constant values $\left(K_{\mathrm{D}}\right)$ [56-60]. This moderate affinity is considered to be crucial for allowing transient association and dissociation events in cell signaling. Indeed, artificially increased affinity using an engineered $\mathrm{SH} 2$ domain (called the pTyr superbinder) has been shown to cause detrimental consequences to cells [61]. While the pTyr-binding pocket, which is present in the $\mathrm{N}$-terminal half and highly conserved in the $\mathrm{SH} 2$ domain, provides the basal affinity for ligand binding with approximately a half of the total binding free energy [62], the hydrophobic pocket present in the C-terminal half of an $\mathrm{SH} 2$ domain provides specificity towards a hydrophobic residue in a peptide ligand. Recent studies suggest that the major positional specificity of an $\mathrm{SH} 2$ domain is conferred by the EF and BG loops which regulate ligand access to specificity pockets in an $\mathrm{SH} 2$ domain. Thus, distinct loop composition and configuration determines whether an $\mathrm{SH} 2$ domain has specificity for a residue at the second, third or fourth position C-terminal to the pTyr residue $[10,11,20,40,63,64]$. The wealth of experimentally solved $\mathrm{SH} 2$ domain-ligand complex structures allows the systematic ultrastructural investigation into how variations in the specificity pocket leads to distinct specificities with bioinformatics tools. Meanwhile, additional subtlety and sophistication in pTyr-peptide discrimination have been demonstrated by a recent study highlighting the importance of permissive and non-permissive residues proximal to pTyr in the ligand sequence [65]. The study provided evidence that local sequence context provides an additional layer of specificity enhancement beyond the general sequence motifs uncovered by regular degenerate peptide library screens $[20,66]$.

\section{The Spt6 SH2 domain: a common ancestor of pTyr recognition?}

The yeast genome encodes only one $\mathrm{SH} 2$ domaincontaining protein, the transcription factor Spt6 [7]. The $\mathrm{C}$-terminal region of the protein, initially predicted to contain a single $\mathrm{SH} 2$ domain, binds to the C-terminal domain (CTD) of the RNA polymerase II [52]. The CTD consists of an abundance of repeats (52 in human, 26 in yeast) of the heptad sequence YSPTSPS, in which each tyrosine, serine, and threonine residues can be phosphorylated. Furthermore, prolines are subjected to cistrans isomerization, adding another layer of complexity and dynamics to the CTD $[67,68]$. The SH2 domain of Spt6 has been considered a prototypical SH2 domain for several reasons. (I) Spt6 is present in yeast that does not contain a PTK, (II) Yoh et al. demonstrated that the Spt6 SH2 domain region binds to Ser-phosphorylated CTD, and (III) Spt6 is conserved in eukaryotes including slime moulds and plants $[7,11,52,69]$. Indeed, the recently solved structures of the C-terminal region of Spt6 revealed that the region actually contains two $\mathrm{SH} 2$ domains in tandem that are intimately associated with each other (Figure 1C) [48-51]. The phospho-binding pocket of the N-terminal $\mathrm{SH} 2$ domain, which contributes to CTD phosphopeptide binding, contains an arginine that is invariant among eukaryotic $\mathrm{SH} 2$ domains $[49,50,52]$. In contrast, the corresponding pocket in the C-terminal SH2 domain lacks an arginine, and NMR titration studies suggest that this pocket is not used for peptide binding. Instead, a positively charged patch on the surface of the C-terminal $\mathrm{SH} 2$ domain participates in CTD binding (Figure 1C) [49,50]. Interestingly, the tandem SH2 domains have shown low affinities (with dissociation constants in the millimolar range) for both pTyr- and pSer-containing peptides derived from the CTD [50]. It is proposed that the binding of the Spt6 tandem $\mathrm{SH} 2$ domains to the polymerase may be significantly enhanced in vivo as the CTD contains numerous repeats of the phosphorylated heptad sequence that can increase the effective local concentration of the binding target for the tandem $\mathrm{SH} 2$ domains [50]. From an evolutionary standpoint, it is likely that the Spt6 SH2 domains provided the prototype for a family of modular domain for the phospho-specific interaction that have later evolved to be specific for phosphotyrosine. Notwithstanding this viewpoint, $\mathrm{SH} 2$ domains have been identified in abundance in protozoans such as choanoflagellates $[7,8,70]$. 


\section{Atypical ligand recognition modes}

Although SH2 domains are the largest group of pTyrbinding modules [5,10], it has been shown that certain SH2 domains have the ability to bind ligands in a tyrosine phosphorylation-independent manner [10,34,71-78]. For example, the SH2 domains of tensins and SAP bind to both phosphorylated and non-phosphorylated forms of ligand peptides [73-75,78,79]. Some SH2 domains feature a secondary site located outside of the primary ligand-binding site to engage a pTyr-ligand protein using two sites $[76,80]$. In this regard, Anderson and colleagues identified a second binding site on the C-terminal $\mathrm{SH} 2$ domain of the phosphoinositide 3-kinase p $85 \alpha$ subunit that binds the Raf family kinase member A-Raf in a phosphorylation-independent manner [80]. The authors posit that the second binding site increases the target selectivity of the SH2 domain. Biochemical and structural analysis illustrated pTyr-independent interaction between the $\mathrm{N}$-terminal $\mathrm{SH} 2$ domain of $\mathrm{PLC} \gamma 1$ and the tyrosine kinase domain of the fibroblast growth factor receptor (FGFR) via a secondary binding site, in addition to the canonical pTyr-binding primary site [76]. In another scheme, an SH2 domain may contain sequence motifs that are recognized by distinct types of modular domains. A long, proline-rich insertion into the DE loop of the Crk SH2 domain (Figure 1B) is recognized by the Src homolgy 3 (SH3) domain of the Abl kinase [47]. Sequence analysis of Crk orthologs suggests that this insertion is of recent evolutionary origin as it is identified only in mammalian species [11]. This provides an example of loop evolution that enriches the pTyr signaling network by introducing a novel interaction.

\section{Interplay between $\mathrm{SH} 2$ and kinase domains}

Among the 90 PTKs in the human genome, 32 are cytoplasmic tyrosine kinases [81]. Notably, 28 of them also contain an SH2 domain in tandem with the kinase domain (with the exceptions of TNK1, ACK, FAK and Pyk2). This suggests a strong physical-functional relationship between the kinase and SH2 domains. Mayer et al. demonstrated that a kinase-associated $\mathrm{SH} 2$ domain promotes phosphorylation of substrates, which they termed processive phosphorylation [82]. In the course of processive phosphorylation, the kinase domain of a cytoplasmic tyrosine kinase phosphorylates a substrate on the tyrosine site, that is then tightly bound by the $\mathrm{SH} 2$ domain, allowing the associated kinase domain to carry out further phosphorylation of the substrate (or a second substrate molecule associated with the first substrate) $[19,83]$. Thus the assembly of SH2-kinase domain cassettes allows the physical association required for function of the two domains [4,5,15]. Moreover, recent bioinformatics analysis of protein sequences for 330 bona fide SH2-binding motifs revealed that tyrosine phosphorylation sites in human proteome are significantly enriched in the vicinity of the $\mathrm{SH} 2$ domainbinding sites [84], which may indicate that processive phosphorylation is a rather common phenomenon. Processive phosphorylation is perhaps unique to the $\mathrm{SH} 2-$ kinase domain combination, because the PTB domain (see below) does not coexist with a tyrosine kinase domain in any human protein [85]. As we discuss later, direct intramolecular interaction between the kinase and SH2 domains is essential for activity in some PTKs, which represents another physical and functional interaction between the two domains and a potential target for treatment in cancer cells.

\section{Multifunctional loops for the SHP SH2 domains}

Interplay between an $\mathrm{SH} 2$ domain and a catalytic domain has also been observed for phosphatases. Pei et al. reported that the $\mathrm{SH} 2$ domains of tyrosine phosphatase SHP-1 regulates its catalytic activity via an autoinhibition mechanism [86]. Since then, structural studies of SHP-1, and its paralog phosphatase SHP-2, have revealed multiple conformations for the SHP phosphatases. The first crystal structure of SHP-2 demonstrated its inactive conformation, in which Asp61 of the DE loop from the N-terminal SH2 domain mimics pTyr moiety and directly blocks the catalytic pocket of the phosphatase domain (Figure 2A) [87]. Interestingly, in this inactive conformation, the cleft between the EF and BG loops of the N-SH2 domain is closed and ligand binding is disabled. A similar inhibitory conformation was also observed for SHP-1 [88]. A recent model proposed that activation of the SHP-1 phosphatase requires binding of a pTyr ligand to the $\mathrm{SH} 2$ domains and a subsequent large structural rearrangement of the $\mathrm{C}$-terminal $\mathrm{SH} 2$ domain to allow dissociation of the $\mathrm{N}$-terminal SH2 domain from the catalytic pocket [89]. A further structural study illustrated that the N-terminal SH2 domain of SHP-2 possesses the ability to act either in the singlepeptide or in the double-peptide binding mode, depending on the peptide sequence [90]. The single-peptide binding mode follows a canonical ligand binding mechanism, i.e., binding to an open cleft between the EF and BG loops (Figure 2B). In the double-peptide binding mode, one of the peptides binds the canonical pocket in a pTyr-dependent manner whereas the other pairs up with the first peptide to form a short antiparallel $\beta$-sheet (Figure $2 \mathrm{C}$ ). The authors propose that such a property of the SH2-dual peptide interaction suggests the $\mathrm{SH} 2$ domain may serve as a scaffold for two ligand molecules.

\section{Phosphorylation-dependent binding partner switching}

Post-translational modification such as tyrosine phosphorylation may act as a switch for some proteins. For instance, the presence or absence of phosphorylation 


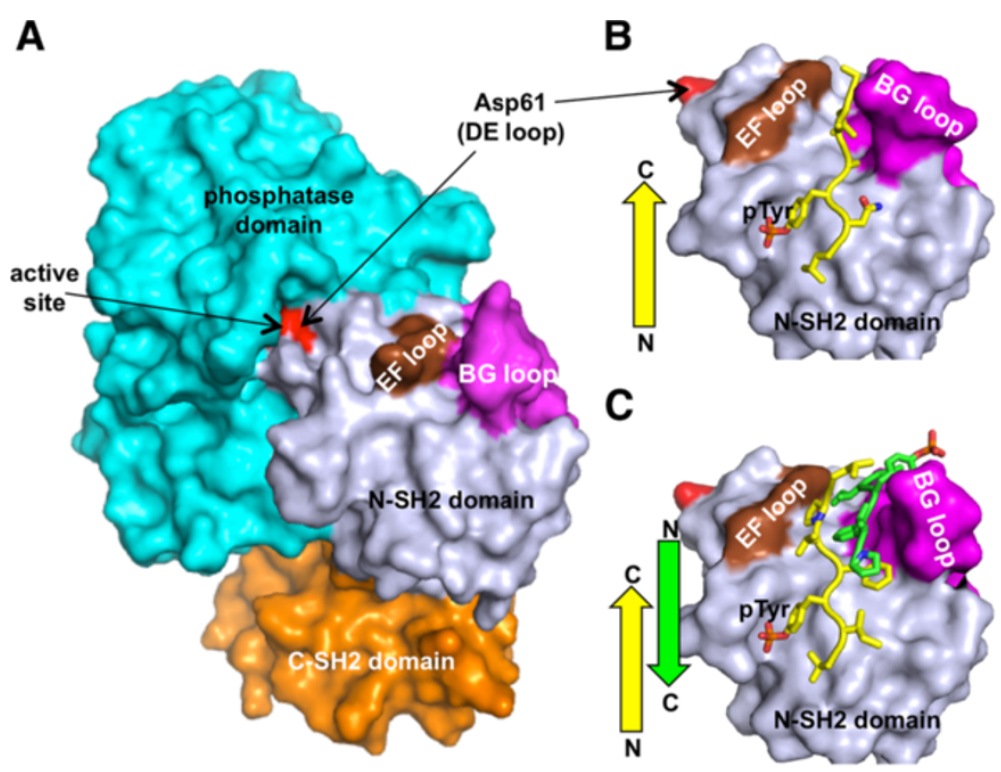

Figure 2 Surface loops in the SH2 domain confer multiple binding modes to the tyrosine phosphatase SHP2. The N-terminal SH2 (N-SH2), C-terminal SH2 (C-SH2) and the phosphatase domains are coloured in light blue, orange, and cyan, respectively. The EF and BG loops of the $\mathrm{N}-\mathrm{SH} 2$ domain are coloured brown and magenta, respectively. Molecular orientation is aligned for the N-SH2 domain, and drawn to scale. (A) The inhibitory state of SHP2 (PDB ID: 2SHP) [87]. The DE loop region of the N-SH2 domain, including the side chain of Asp61 (coloured red), mimics a pTyr substrate and blocks the active site of the phosphatase domain. In this conformation, the BG loop contacts the EF loop and inhibits ligand binding. (B) The 1:1 binding mode (PDB ID: 3TL0) [90]. The bound LNpYAQLW peptide is coloured yellow. The C-terminal region of the single peptide binds to a cleft between the EF and BG loops. (C) The 1:2 binding mode, in which the two identical peptides, with a sequence VIpYFVPL, form a short, antiparallel $\beta$-sheet and bind to a single SH2 domain (PDB ID: 3TKZ) [90]. The BG loop is positioned to accommodate the two peptides.

may provide a mechanism for alternative binding to distinct protein partners [84]. This type of regulation is underscored in the multifaceted interaction between the T-cell receptor subunit CD3e and either the ZAP-70 tandem SH2 domains or the Eps8L1 and the $\mathrm{N}$-terminal NCK SH3 domains (Figure 3) [91-93]. CD3e harbours both an immunoreceptor tyrosine-based activation motif (ITAM) and a PxxDY motif. These two motifs overlap at Tyr166, which may be phosphorylated (Figure 3). While phosphorylation of Tyr166, along with Tyr177 in the
ITAM motif, promotes the binding of the tandem ZAP70 SH2 domains, the phosphorylation of Tyr166 also abrogates SH3 domain binding via the PNPDY motif (Figure 3) [91-93]. Bioinformatics analysis suggests that there exist a plethora of such phosphorylation sites on signaling proteins which could act as regulatory switches for selective protein-protein interactions [84]. Moreover, phosphorylation-dependent partner switching has been documented to also occur on other modular domainmediated interactions, as elucidated below for the

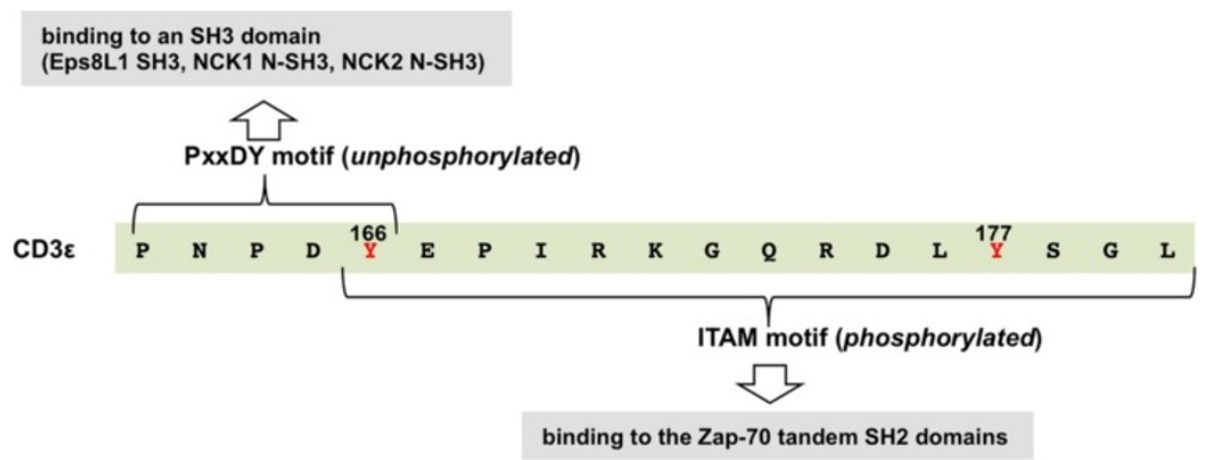

Figure 3 Binding partner switch induced by tyrosine phosphorylation. The sequence of the T-cell receptor subunit, CD3E, contains two interaction motifs overlapping at a tyrosine phosphorylation site. The two phosphorylation sites Tyr166 and 177 are coloured red. The binding partners of the motifs, depending on the phosphorylation state, is schematically depicted as highlighted boxes. 
interaction between E-cadherin and the PTB and HYB domains [94-96].

\section{The PTB domain}

The phosphotyrosine-binding (PTB) or phosphotyrosineinteracting domain, first identified in the adaptor protein Shc [97-99], is the second largest family of pTyr-binding modules. Approximately 60 human proteins contain a PTB domain [85]. Although none have been identified from yeast or plants so far, two PTB domains have been found in the slime mould Dictyostelium discoideum [85], and 31 in the choanoflagellate Monosiga brevicollis [100]. The proteins harbouring a PTB domain strictly act as adaptors or molecular scaffolds [101], with possible exceptions at least in $M$. brevicollis, where multiple tyrosine kinases that contain a PTB domain have been identified [6]. Indeed, biochemical studies indicate that the PTB domain of the $M$. brevicollis tyrosine kinase HMTK1 assists in targeting of a pTyr-containing substrate peptide [102]. While a third of all PTB-containing proteins identified contain a single copy of the domain, the remaining two-thirds feature a PTB domain occurring in combination with other modular domains such as $\mathrm{SH} 2$, SH3, PDZ or SAM [85]. PTB domain-containing proteins are involved in a host of signaling processes, including those involving receptor tyrosine kinases, cytokines and lipoprotein receptors, and cellular functions such as cell division and cell-cell adhesion [101].

\section{Architecture of the PTB domain}

Johnson and colleagues divided the PTB domain family into three classes, namely Shc-like, IRS-like and Dablike, based on the domain structure [85]. Although, ligand recognition by the Shc-like and IRS-like PTB domains is considered to be tyrosine phosphorylationdependent, the majority of the remaining PTB domains, classified as the Dab-like domains, are phosphorylationindependent in ligand binding [85]. Structural analysis has revealed that the PTB domains are characterized with the pleckstrin homology $(\mathrm{PH})$ domain "superfold", although they share little sequence identity with $\mathrm{PH}$ domains [103]. All PTB domains encompass a minimal fold containing two orthogonally arranged $\beta$-sheets composed of seven anti-parallel $\beta$-strands (Figure 4A). The $\beta$-sheets pack against two $\alpha$-helices, $\alpha 2$ and $\alpha 3$ (nomenclature of the secondary structures follows that defined in [104]). The Shc-like and Dab-1-like PTB domains have an additional N-terminal helix ( $\alpha 1$ helix), whereas the IRS-1-like domains have an extremely truncated $\alpha 2$ helix, which represents the minimal domain fold (Figure 4A) [105-109]. The PTB domains bind peptide ligands in an L-shaped hydrophobic groove contoured by the $\beta 5$ strand and the $\alpha 3$ helix [110]. The peptide usually docks with its N-terminal residues forming an anti-parallel $\beta$-strand and the $\mathrm{C}$-terminal of the peptide arranged as a type I $\beta$-turn.

\section{Tyrosine phosphorylation-dependent and independent ligand binding}

Similar to the SH2 domain, PTB domains may bind tyrosine phosphorylation sites in cellular proteins. Proteomic studies have revealed that the two domain families may in fact target overlapping pTyr sites with micromolar affinities [57-59,113]. However, unlike SH2 domains, the specificity of a PTB domain is primarily focused towards amino acids N-terminal to the pTyr residue in a peptide, most commonly in an NPXPY or NPXY sequence motif [114]. Moreover, the majority of PTB domains prefer a non-phosphorylated tyrosine residue. In fact, phosphorylation of a peptide is inhibitory to binding to some members of the Dab-1-like PTB domain group [85]. Interestingly, a number of PTB domains can bind the head groups of inositol phosphates with varying affinities, a function observed also in some of the structurally similar PH domains $[85,110]$. PTB domains appear to commonly bind to phospholipids through a patch of basic residues on the surface of the domain, although the actual residues that bind to the phospholipid are variable or not resolved for most PTB domains [85,103]. Interestingly, a phosphopeptide and a phospholipid can compete against each other in binding to a PTB domain, as has been shown for the Shc PTB domain [115].

\section{The versatile Numb PTB domain}

Numb is an adaptor and endocytic protein that plays an important role in asymmetric cell division and embryogenesis [116]. It contains a Dab-1-like PTB domain indispensable for its function. Biochemical and structural studies have suggested that the Numb PTB domain is capable of binding to either non-phosphorylated sequences that contain an NXX[Y/F] motif or pTyrcontaining sequences $[104,111,116,117]$. Structural analysis unraveled the molecular basis of promiscuous binding by the Numb PTB domain to peptides that possess distinct primary and secondary structures [104,111]. Figure $4 \mathrm{~B}$ shows the complex structure of the Numb PTB domain in complex with a non-phosphorylated peptide that contains the sequence NMSF derived from the Numb-associated kinase (NAK) [111]. Interestingly, mutation of the sequence from NMSF to NAAF resulted in 15-fold increase in binding affinity, implying that the physiological association between the Numb PTB domain and NAK may not be optimized for high affinity [111]. Moreover, the Numb PTB domain provides a binding site for another domain in an isoform-specific manner. The p72 and p66 isoforms of Numb contain an 11-residue insert within the PTB domain after the 


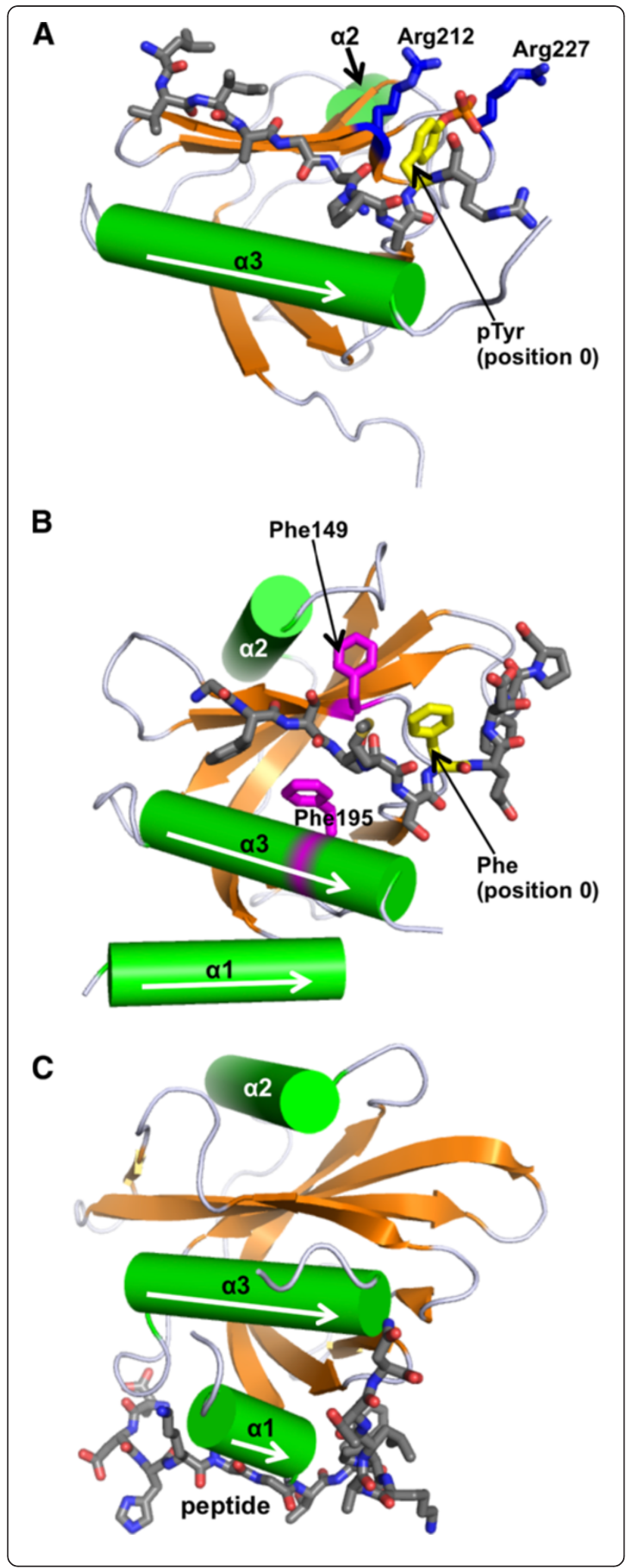

Figure 4 Diversity in ligand recognition in the PTB domain family. PTB domains are shown in ribbon representations, with a-helices in green, and $\beta$-strands in orange. Bound peptides are drawn as gray sticks. (A) The PTB domain of IRS-1 bound to a pTyr-containing peptide derived from interleukin 4, containing an NPApY sequence (PDB ID: 1IRS) [105]. The two arginine residues, Arg212 and Arg227 (coloured blue), provide electrostatic contacts with pTyr at position 0 (coloured yellow). (B) The Numb PTB domain bound to an NAKderived peptide (PDB ID: 1DDM) [111]. The peptide contains an NMSF sequence, but not a tyrosine. Phe149 and Phe195 (coloured magenta) of the PTB domain are essential for peptide binding. (C) The tensin2 PTB domain bound to a peptide derived from DLC-1 (PDB ID: 2LOZ) [112]. The peptide, which does not contain an NXX $[Y / F]$ motif, binds to a novel site on the PTB domain that involves the a1 helix.

$\alpha 2$ helix, which serves as a binding site for the PDZ domain of LNX (Ligand-of-Numb), an E3 ubiquitin ligase required for isoform-specific Numb degradation [118]. Recently, we found that Numb serves as a new player in epithelial to mesenchymal transition, a critical step in cancer progression and metastasis $[94,119]$. The Numb PTB domain binds to the $\mathrm{N}^{751} \mathrm{VYYY}$ motif located in the cytoplasmic region of E-cadherin, but phosphorylation of the motif by Src results in dissociation of the PTB domain, suggesting that $\mathrm{Src}$ activation negatively regulates the interaction between Numb and E-cadherin [94].

\section{The tensin family SH2 and PTB domains}

Unlike SH2 domains, which often coexist with a kinase or phosphatase domain in a protein, the human PTB domain-containing proteins invariably lack a catalytic domain, with the single exception of the presence of a PTP-like domain in the tensin family (see a later section for detail) [85,120,121]. Tensins $1-4$ are focal adhesion proteins that contain an $\mathrm{SH} 2$ domain and a PTB domain in tandem [122]. Similar to the tensin-like lipid and tyrosine phosphatase PTEN [123], tensins 1-3 have been identified as tumour suppressors. Tensins interact with another tumour suppressor, deleted in liver cancer 1 (DLC1), and suppress focal adhesions and cell migration in various cancers $[122,124]$. The SH2 domain of tensin3 is itself phosphorylated by the Src kinase [125]. Lowy and colleagues suggest that tyrosine phosphorylation on the tensin3 $\mathrm{SH} 2$ domain provides a mechanism for controlling ligand binding and that phosphorylation of the SH2 domain by the Src kinase endows tensin3 with proto-oncogenic properties [125]. The study also indicated that binding to DLC1 was not dependent on tyrosine phosphorylation of the $\mathrm{SH} 2$ domain of tensin3, whereas binding to some other ligands such as the focal adhesion kinase was enhanced by the $\mathrm{SH} 2$ phosphorylation. Another study showed that the $\mathrm{SH} 2$ of tensin2 has the ability to bind non-phosphorylated DLC1 [78]. These two observations indicate that the phosphorylation state 
of the ligand proteins as well as that of the $\mathrm{SH} 2$ domain can regulate SH2-ligand interactions in tensins [78,125]. Moreover, the PTB domain of tensin2 displays a novel peptide binding mode. Although it was observed that the tensin1 PTB domain can bind an NPXY peptide in a canonical manner [126], as well as a DLC1 peptide via a yet uncharacterized mode [75], the tensin2 PTB domain, which can also bind the NPXY motif [127], has been determined to utilize its $\mathrm{N}$-terminal helix $(\alpha 1)$ to engage a non-NPXY site in DLC1 [112]. The binding surface in the latter PTB domain is opposite to the canonical NPXY peptide binding site and the peptide ligand adopts an elongated conformation rather than the conventional $\beta$-turn structure (Figure 4C) [112]. These observations indicate the presence of peptide binding surface specializations among the tensin family PTB domains.

\section{Atypical pTyr recognition domains and proteins The HYB domain}

Hakai, a protein that binds to E-cadherin in a tyrosine phosphorylation-dependent manner, serves as an E3 ubiquitin ligase for the latter and induces endocytosis and degradation of E-cadherin [95]. Hakai is also known to interact with an RNA-binding protein, the PTBassociated splicing factor, that targets mRNAs encoding cancer-related proteins [128]. Hakai resembles the E3 ligase $\mathrm{c}-\mathrm{Cbl}$ in that they both harbour a pTyr binding domain (an $\mathrm{SH} 2$ domain in the case of $\mathrm{c}-\mathrm{Cbl}$ ), a region homologous to the RING finger motif and a proline-rich region [95]. The pTyr binding region in Hakai was initially thought to be an $\mathrm{SH} 2$ domain, but this assumption was proven to be incorrect by recent studies showing that a unique, zinc co-ordinated domain formed by the dimerization of two Hakai monomers is responsible for p'Tyr recognition $[95,96]$. This novel pTyr recognition domain, now named the HYB domain, is formed via the dimerization of a 100-residue stretch, including the RING finger motif, in an anti-parallel orientation (Figure 5A). The dimer coordinates six zinc ions with a total of 24 Cys or His residues (four residues per zinc ion; Figure 5A). Crystallographic and NMR titration experiments revealed that the positively charged pTyrbinding pocket, which is responsible for binding phosphorylated E-cadherin, is situated in the interface of the dimer. In particular, phosphorylation of the $\mathrm{N}^{751}$ VYYY motif on the Tyr residues and acidic residues flanking the motif are necessary for binding to the HYB domain, with a $K_{\mathrm{D}}$ value of $7.2 \mu \mathrm{M}$ for the $\mathrm{N}^{751} \mathrm{VYpYY}$ containing E-cadherin peptide [96]. Because this motif also mediates the binding to the Numb PTB domain when it is not phosphorylated [94], it provides yet another example of the tyrosine phosphorylation-dependent binding partner switch. Interestingly, the HYB domain has also been identified in the testis-specific ubiquitin ligase
ZNF645, but its target specificity is apparently distinct from that of the Hakai HYB domain [96]. Moreover, sequence inspection suggests that the Numb-associated E3 ligase LNX may contain an HYB domain [96]. Thus, the HYB domain appears to be a recurring feature in certain E3 ligases and its presence in cell adhesion regulatory proteins such as Hakai suggests a role for this domain in cell-cell adhesion and cancer metastasis [129]. The HYB domain is likely conserved through evolution as a sequence search identifies HYB-like domain sequences in different animals and plants with complete conservation of the zinc-coordinating residues (Figure 5B).

\section{The GEP100 PH domain}

The $\mathrm{PH}$ domain was first described in pleckstrin, a substrate of protein kinase C (PKC) [131,132]. It has since been identified in a large number of signaling and cytoskeleton-associated proteins. By virtue of its ability to bind phospholipids, in particular inositol phosphates, the $\mathrm{PH}$ domain plays an important role in targeting the corresponding protein to the plasma membrane $[103,133]$. Interestingly, some $\mathrm{PH}$ domains are found to bind to proteins in a phosphorylation-dependent manner [110,133-137]. The PH domain of GEP100 (also known as BRAG2 or IQSEC1), a guanine nucleotide exchange factor for the small GTP-binding protein Arf6, binds to the EGF receptor residues pTyr1068 and pTyr1086, both of which are part of a YXNQ motif [138]. These two pTyr sites are also known to recruit the adaptor proteins Grb2 and Shc as well as the transcription factor STAT3 via their SH2 and/or PTB domains [139,140]. However, it has been shown that the GEP100 pathway may not necessarily interfere with the Grb2 pathway in breast cancer [141]. Co-expression of GEP100 and Arf6 turned non-invasive MCF7 cells to become invasive upon EGF stimulation $[138,142]$. Therefore, this pathway is a potential new target for breast cancer therapeutics. The crystal structure of the GEP100 PH domain alone has been solved (PDB database entry $3 \mathrm{QWM}$ ), but a $\mathrm{PH}$ domain - pTyr-peptide complex structure is still missing, since synthetic pTyr1068 and 1086 peptides immobilised on a carrier membrane can directly bind to the GEP100 $\mathrm{PH}$ domain, but have a surprisingly low binding affinity to it in solution (S.F. et al., unpublished data). The reason for this currently remains unclear. By contrast, the native EGFR receptor is effectively precipitated by the GEP100 PH domain upon activation, i.e., when phosphorylated on pTyr1068 and/or pTyr1086.

\section{The $P K C \delta$ and $P K C \theta C 2$ domains}

The C2 domain belongs to one of the largest domain families with over 200 members in human [103,143]. This $\sim 130$ residue module primarily binds to phosphatidylserine in the cell membrane in a calcium-dependent 
A
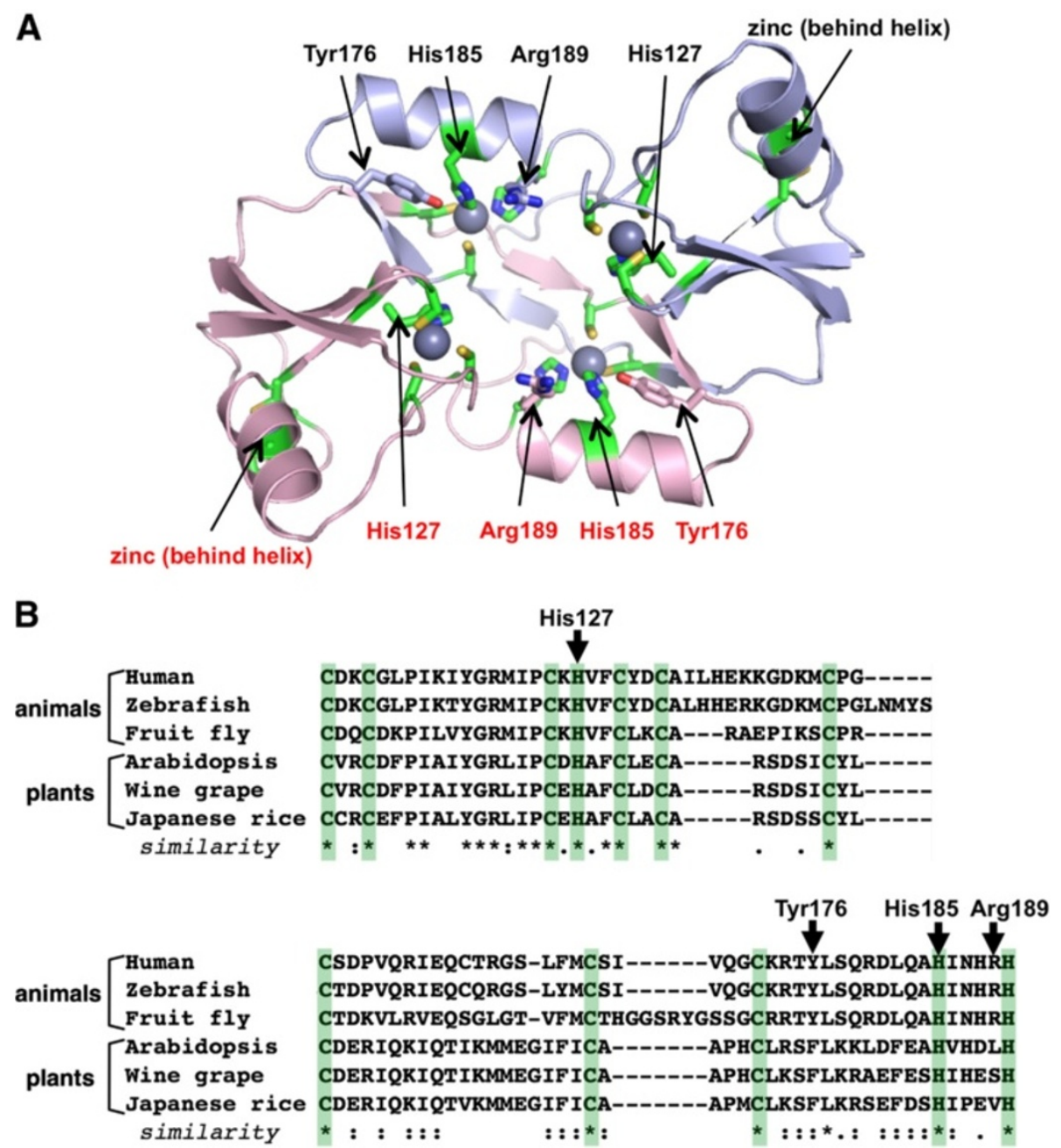

Figure 5 The structure and sequence conservation of the HYB domain. (A) The HYB domain is coordinated with six zinc ions. Shown is the homo-dimeric structure of the Hakai HYB domain (showing the two chains with different colours) (PDB ID: 3VK6) [96]. Zinc ions are depicted as spheres. The 24 residues (12 per monomer) coordinating the zinc ions are shown as green sticks. The four residues, His127, Tyr176, His185, and Arg189 from each monomer, identified as sticks, mainly contribute to pTyr binding by providing a positively charged pocket. (B) HYB domain-like sequences identified in animals and plants. The alignment was generated by the program MAFFT [130]. The 12 zinc-binding residues are shaded green, showing that all of them are strictly conserved within these species. The human Hakai HYB domain was aligned with following sequences with UniProt IDs: zebrafish (Q5RGV5), fruit fly (Q9VIT1), Arabidopsis thaliana (Q9LFC0), wine grape (F6HKX7), and Japanese rice (Q0IWQ6).

manner. The $\mathrm{C} 2$ domain has a core structure of a $\beta$ sandwich formed by eight antiparallel strands (Figure 6A). The calcium binding sites are located in the inter-strand loops [103]. It has been shown that C2 domains have disparate calcium dependency for activity and a weak affinity for most phospholipids, suggesting that they may have other binding functions [103,144]. Benes et al. demonstrated that the $\mathrm{C} 2$ domain of the Ser/Thr kinase PKC $\delta$ can recognize a pTyr peptide derived from CDCP1 (CUB domain-containing protein 1) in a sequence-specific manner, with a $K_{\mathrm{D}}$ of $240 \mathrm{nM}$ $[145,146]$. CDCP1, a transmembrane protein overexpressed in a number of cancers, is a substrate of the Src family kinases [147]. The C2 domain-containing PKC $\delta$ is the first example of a Ser/Thr kinase displaying a pTyr binding capability. Subsequently, the $\mathrm{C} 2$ domain of PKC $\theta$, which shares $70 \%$ sequence identity with that of PKCS [145], was also found to bind to the tyrosinephosphorylated CDCP1 peptide with a similar affinity [148]. Importantly, this binding is the key for activation of PKC $\theta$ from an autoinhibitory state, which is mediated by an intramolecular interaction involving the $\mathrm{C} 2$ domain. The crystal structure of the PKC $\mathrm{C} 2$ domain in complex with an optimal pTyr peptide demonstrates that the pTyr-peptide binds in an elongated conformation across two $\beta$-sheets (Figure 6A). The $\mathrm{C} 2$ domain coordinates the phosphate group of pTyr in a deep pocket using positively charged lysine and arginine 
A

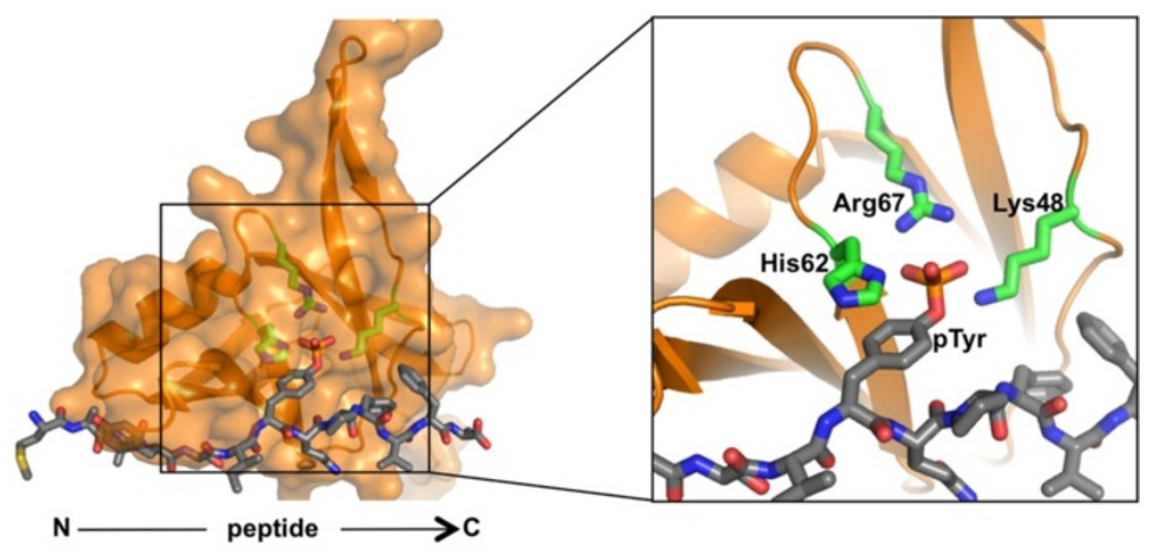

B
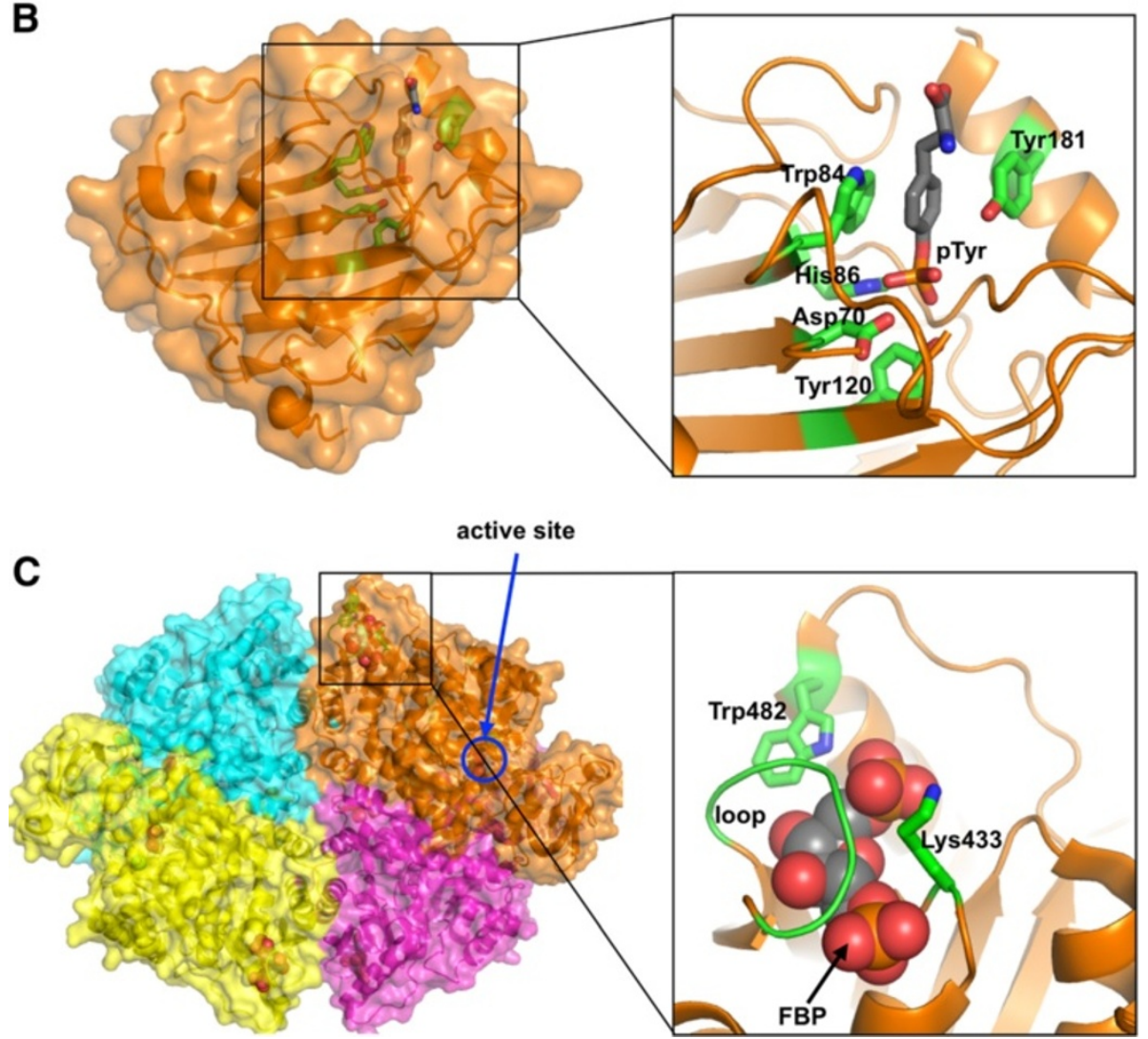

Figure 6 Atypical pTyr recognition proteins. On the left panels, molecular surface of each protein is overlaid on ribbon representation. (A) The C2 domain from the human PKC $\delta$ bound to a pTyr-peptide (PDB ID: 1YRK) [145]. The peptide is shown as grey sticks. Positively charged residues (green sticks) of the C2 domain that engage the pTyr moiety are shown to highlight the histidine-phenyl ring stacking feature. (B) pTyr binding by the human RKIP (PDB ID: 2QYQ) [149]. The structure features a deep pocket complementary to the pTyr side chain. The structure also highlights the lack of lysine and arginine in the binding pocket. (C) The homo-tetrameric active form of the human PKM2 bound to FBP (PDB ID: 3BJF) [150]. Each monomer is depicted with a different colour. The allosteric activator FBP is drawn as space-filling models. The distal active site from a monomer is identified with a blue circle. In the inset, the "lip" of the FBP-binding pocket created by the Lys433 and Trp482 residues and a loop region is coloured green. A pTyr ligand also binds to this region, and promotes the release of the FBP molecule, which results in inactivation of PKM2.

residues (Figure 6A). Moreover, the phenyl ring of pTyr is stabilized by a unique ring-stacking interaction with a histidine residue that is proximal to the phosphatebinding arginine residue (Figure 6A) [145].

\section{The catalytically inactive PTP domain}

The protein tyrosine phosphatase (PTP) family proteins dephosphorylate a pTyr residue of substrate proteins ("erasers" in the toolkit). There are 107 PTPs in human, 
of which 61 phosphatases are classified as the dualspecificity phosphatase subfamily, which also possess Ser/Thr phosphatase activity in addition to pTyr dephosphorylation [151]. The PTP family phosphatases share a conserved domain fold and possess a catalytic cysteine in the $\mathrm{HCX}_{5} \mathrm{R}$ motif located on the active site loop [152-154]. However, sequence analysis led to the identification of PTP domain homologs that lack the catalytic cysteine or another essential residue in the motif (Figure 7) [153,154]. Such findings were first described for the protein named STYX (phospho-serine or threonine or tyrosine interaction protein), which is similar in sequence to PTPs, except for a Cys to Gly substitution in the signature motif (Figure 7) [152,155]. This renders the STYX protein unable to catalyze dephosphorylation. However, the STYX Gly-to-Cys mutant conferred catalytic activity to the protein and the mutant demonstrated phosphatase activity for both the pTyr and pThr residues [152]. Since then, many more PTP-like domains have been identified [153,154,156-159]. For example, EGG4

\begin{tabular}{|c|c|}
\hline РTP1B & VVVHCSAGIGRSGT \\
\hline PTEN & AAIHCKAGKGRTGV \\
\hline EGG4 & VVIHDHLGVSRAAC \\
\hline Tensin 1 & VVLHNKGNRGRIGV \\
\hline Auxilin & CVVHCLDGRAASSI \\
\hline STYX & $\begin{array}{l}\text { VLVHENAGISRSAA } \\
\text { gain-of-function mutation }\end{array}$ \\
\hline MK-STYX & $\begin{array}{l}\text { ILIFSTGISRSCA } \\
\text { HA gain-of-function mutations }\end{array}$ \\
\hline HD-PTP & $\begin{array}{c}\text { I IVHCSSGVGRTGA } \\
\text { gain-of-function mutation } \\
\text { A }\end{array}$ \\
\hline \multicolumn{2}{|c|}{$\begin{array}{l}\text { Figure } 7 \text { Mutations that confer PTP activity to catalytically-dead } \\
\text { phosphatases. The catalytic signature motif sequences are } \\
\text { extracted from the active phosphatases PTP1B and PTEN, along with } \\
\text { five phosphatase-like domains. The His, Cys and Arg residues in the } \\
\text { HCX } R \text { motif, conserved among active PTP domains, are coloured } \\
\text { red. The arrowhead indicates the catalytic cysteine. Mutations that } \\
\text { have experimentally proven to restore catalytic activity are also } \\
\text { indicated, for STYX [152], MK-STYX [157] and HD-PTP [159]. EGG4/5, } \\
\text { Tensin1 and auxilin are predicted to be devoid of PTP activity owing } \\
\text { to the lack of a signature motif residue [121,158]. }\end{array}$} \\
\hline
\end{tabular}

and EGG5, two almost identical proteins in Caenorhabditis elegans, contain a PTP-like domain without a catalytic Cys residue (Figure 7). Cheng, et al. reported that the domain binds to tyrosine residues in the activation loop of a kinase that regulates the oocyte-to-embryo transition [158]. This interaction is enhanced, although not absolutely necessary, by phosphorylation of the tyrosines. Haynie and Ponting have proposed that the N-terminal regions of two proteins, tensin 1 and auxilin, are PTP-like domains, in which the former lacks the catalytic cysteine, whereas the latter lacks the arginine of the $\mathrm{HCX}_{5} \mathrm{R}$ motif (Figure 7) [121]. Interestingly, the PTP-like domain is immediately followed by a C2 domain in both proteins, and the PTP-C2 unit is homologous to the tumour suppressor PTEN [160,161]. The PTP domain of PTEN possesses an intact signature motif, and it displays phosphatase activity for both phospholipids and phosphotyrosine [162]. It is therefore possible that the PTP-like domain of tensin 1 and auxilin may be a phosphotyrosine or phospholipid binding domain. Many PTP-like domains are awaiting functional characterization.

\section{Raf-1 kinase inhibitory protein}

Raf-1 kinase inhibitory protein (RKIP), also known as phosphatidylethanolamine binding protein 1, suppresses Raf-1 kinase activity in the MAP kinase pathway [163]. RKIP binds to a 24 amino acid stretch in the N-terminal of the Raf-1 kinase which has a central element $\left(S^{338} S Y Y^{341}\right)$ regulated by phosphorylation [164]. Substitutions in the ligand binding site of RKIP compromise the stability of the phosphorylated Raf-RKIP complex. Additionally, mutation of the Ser residues or Tyr341 on the Raf-1 kinase motif disrupts its interaction with RKIP. This suggests that RKIP contains a novel phosphoamino acid binding domain [165]. The structure of RKIP bound to pTyr shows that RKIP indeed contains a deep pocket molded complementary to the shape of the pTyr side chain (Figure 6B) [149]. NMR titration studies further confirmed that the pocket region is the binding site

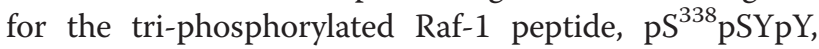
with a $K_{\mathrm{D}}$ value of $45 \mu \mathrm{M}$ [166]. However, direct, physiological or structural, evidence for complex formation is required before RKIP can be classified as a bona fide pTyr binder.

\section{Searching for novel pTyr recognition proteins}

In the above sections, we have explored that, in addition to the $\mathrm{SH} 2$ and PTB domains, there are more than a handful of examples of atypical domains that can recognize and bind $\mathrm{pTyr}$-containing target proteins. So does nature have more domain members capable of pTyr-epitope binding that remain to be identified? Recent advances in proteomic technologies are starting to shed light on this question. Christofk et al. employed the 
SILAC (stable isotope labeling of amino acids in cell culture) technique in combination with a pTyr-peptide library to identify novel pTyr-binding proteins from mammalian cell lysates [150]. Whereas the majority of proteins identified were $\mathrm{SH} 2$ or PTB domain-containing proteins, as expected, the screening also identified pyruvate kinase, a protein that does not have any known pTyr-recognition domain. Pyruvate kinase (PK) regulates the final rate-limiting step in glycolysis that converts cellular metabolism from an anaerobic to an aerobic process. The M2 isoform of the PK (PKM2) is the only form of PK used for glycolysis in cancer cells, and it is also the only one of the four isoforms that has the ability to bind to pTyr targets $[167,168]$. The structure of hPKM2 illustrates a homo-tetramer with each monomer binding a fructose-1,6-bisphosphate (FBP) molecule in a site distal to the active site (Figure 6C) $[150,169]$. Phosphotyrosine ligand binding may be a key event in modulating PK activity regulated by the allosteric activator FBP [150]. The study demonstrated that PKM2 binds pTyr peptides on the lip of the FBP binding pocket and acts as a negative regulator of PK activity (Figure 6C) [150]. Binding of the phosphopeptide releases FBP from the active tetrameric form of PKM2 and dissociates the enzyme into inactive dimers [168].

More recently, Christofk et al. identified a handful of potential pTyr-binding proteins from SILAC experiments. These include the serine/threonine-protein kinase WNK1, 5-formyltetrahydrofolate cyclo-ligase, glycerol-3phosphate dehydrogenase, vimentin, 2,4-dienoyl-CoA reductase, and the T-complex protein 1 subunit $\eta$ [170]. Although biochemical characterization is required to ascertain if these candidates are true pTyr-binders, results from this study suggest that there may be more pTyr recognition domains or proteins in nature that await to be discovered.

\section{Phosphotyrosine recognition domains and therapeutic applications}

New insights into the molecular basis of cancer were generated already decades ago by the analysis of $\mathrm{SH} 2-$ domain containing oncoproteins such as v-Src $[27,171]$. $\mathrm{SH} 2$-domain containing proteins have been implicated in many diseases, including immune-related disorders, metabolic syndromes, osteopathologic conditions and different cancers [10,172]. Mutations in the SH2 domains that cause malignancies fall usually into one of three categories: missense mutations of amino acids involved in target binding, mutations in residues that regulate catalytic activity or mutations on the $\mathrm{SH} 2$ domain, distal to the module core, that affect the architectural integrity of the $\mathrm{SH} 2$ domain [16]. A number of disease-causing mutations on $\mathrm{SH} 2$ domains have been reported as compiled by Liu et al. [10] and Lappalainen, et al. [173], including mutations related to the Noonan syndrome, juvenile myelomonocytic leukemia and the Xlinked lymphoproliferative syndrome. X-chromosomelinked agammaglobulinemia (XLA) is an example of a disease where mutations are present in the $\mathrm{SH} 2$ domain of the Bruton's tyrosine kinase (BTK), and many of these mutations are located on the pTyr-ligand binding site, including the indispensable arginine of the pTyr-binding pocket as well as BG loop residues [16,173]. Moreover, Hong et al. demonstrated that the BTK SH2 domain binds to phospholipids and the XLA-causing mutations alter lipid binding selectivity [174]. In another example, multiple point mutations within the transcription factor STAT3 SH2 domain have been identified and linked to large granular lymphocytic leukemia and the hyper-IgE syndrome $[175,176]$. In conjunction with the identification and study of $\mathrm{SH} 2$ domain-related diseases, small molecule inhibitors of $\mathrm{SH} 2$ domains, $\mathrm{SH} 2$ domaincontaining proteins or $\mathrm{SH} 2$ binding partners, are being developed with some success as therapeutic reagents, although the development of phosphomimetics faces hurdles due to the strong charge of the phosphate group $[177,178]$. Besides SH2 domains, mutations in the PTB domain have also been linked to diseases such as coronary heart disease and type II diabetes [85].

Biochemical and structural studies have demonstrated that direct intramolecular interactions between the $\mathrm{SH} 2$ and kinase domains are required for kinase activation in some PTKs $[15,16,36]$. In the Fes kinase, electrostatic interactions and shape complementarity between residues from the $\mathrm{SH} 2$ domain and the $\alpha \mathrm{C}$ helix of the kinase domain stabilize the active state of the kinase. Similarly, in the Abl kinase, interaction between Ile164 of the SH2 domain and Thr291/Tyr331 in the kinase domain $\mathrm{N}$ lobe is essential for activity [179]. Subsequently, this interface has been investigated intensively as a target for cancer intervention. A successful approach was the creation of a protein-based agent called the monobody, derived from the fibronectin type III (FN3) domain with engineered loops designed for high affinity binding to a specific target molecule [180]. Koide and colleagues created a monobody engineered to selectively bind the SH2 domain of the Abl kinase [181]. They further generated another monobody that targets the SH2kinase interface that involves Ile164 and then connected the two monobodies with a linker. The resulting tandem monobody disrupted the interface between the $\mathrm{SH} 2$ and kinase domains to inhibit the catalytic activity of the deregulated fusion kinase $\mathrm{Bcr}-\mathrm{Abl}$, both in vitro and in vivo [179].

Due to its independently folding nature, a modular domain can often be successfully used as a tool in proteomic research. Jadwin et al. termed this "domainomics" [182]. In particular, applications of phosphotyrosine- 
recognition domains have been reported for therapeutic and diagnostic purposes. SH2 and PTB domain-based probes have been developed and used to profile global pTyr landscapes using innovative assays such as the peptide dot blotting, Far Western blotting and oligonucleotide tagged multiplex (OTM) assays [183-186]. The OTM assay is designed for quantitative multiplexed profiling of tyrosine-phosphorylated proteins from cell extracts using DNA-tagged $\mathrm{SH} 2$ domains, and has been successfully harnessed to discriminate tyrosine phosphorylation states in tumour cell lines and leukemia samples from patients [184]. Similarly, Machida et al. reported application of domain-based probe technology to profile lung cancer cell lines, and demonstrated significant correlation between EGFR mutations and the Grb2 SH2 and ShcA PTB domain probe signals, suggesting a diagnostic value [187]. A potential for application of SH2 domains as non-invasive intracellular imaging or as inhibitor reagents has also been demonstrated. An $\mathrm{SH} 2$ domain from Grb2 or PLC 1 fused with a protein transduction tag (the TAT tag) [188] was used for SH2 domain delivery into cells. These TAT-tagged SH2 domains showed anti-tumour effects [189,190]. In addition, the TAT-tagged Grb2 SH2 domain can be used as a molecular probe for monitoring EGFR localization in cells [191].

$\mathrm{SH} 2$ domains have also been incorporated as a biosensor molecule that functions in live cells. Wang et al. created a bipartite Src reporter biosensor protein that contains an SH2 domain and a Src kinase substrate fused, respectively, with the cyan and green fluorescent proteins [192]. Upon phosphorylation of the substrate by endogenous Src kinase, the $\mathrm{SH} 2$ domain of the biosensor binds to the substrate in cis, and produces a change in the emission spectrum. Using the Src reporter, the authors successfully visualized kinase activity in cells. In another example, an engineered adenocarcinoma-derived cell line that expresses an EGFR biosensor has been developed [193]. This cell line expresses the Grb2 SH2 domain fused to the green fluorescent protein, and can be used to monitor EGFR internalization upon EGF stimulation. The cell line may provide a useful tool for highthroughput drug screening since effects of drug candidates on modulating EGFR activity can be monitored in live cells.

Lastly, understanding the evolution of phosphotyrosine recognition domains may inform cancer research and treatment. In general, the degree of network complexity in the phosphotyrosine signaling system has increased during the course of evolution, and genetic events, such as gene duplications to create paralog proteins and gene fusions to create multi-domain proteins, played a major role in expanding the network scale $[4,11]$. Robustness of the signaling network is partly conferred by network redundancy and a collection of feedback loops or cross-talks [194]. The network evolution creates highly connected conserved nodes, called network hubs, and cancer-causing mutations tend to be observed for the network hub proteins [194]. Besides, Kitano argues that cancer cells hijack the cellular signaling mechanisms for their network robustness [195]. We have recently analyzed the evolutionary origins of human pTyr signalling circuits in 19 eukaryotic species by identifying ortholog proteins of the human circuit components in each species (Figure 8) [8]. The 19 species were classified into three groups (primitive organisms, bilaterians, and vertebrates) based on their evolutionary distances from humans. In this study, a pTyr signalling circuit is defined to comprise a tyrosine kinase, a substrate of the tyrosine kinase, and an $\mathrm{SH} 2$ or PTB domain that binds to the tyrosine-phosphorylated site. Statistical analysis showed that the circuits for intracellular (cytoplasmic) signalling (Figure 8: $a, b, c, d$, and $e$ ) largely originate from primitive species. Circuits that involve receptor tyrosine kinases which phosphorylate cytoplasmic substrates (Figure 8: $a, f, c, d$, and $e$ ) mainly originate from bilaterians. Conversely, vertebrate-origin circuits are enriched with membrane protein substrates that are phosphorylated by primitive-origin cytoplasmic kinases (Figure 8; $g, b, h, i$ and $e$ ) in a tissue-specific manner. This study underlined the importance of network hubs as hotspots for tumourigenesis, as high frequency cancer pTyr sites are involved in more circuits than low frequency sites, and kinase substrate proteins that contain a PTK, SH2 or PTB domain are more frequently recruited for cancer signalling [8].

\section{Future perspectives}

The genome sequence analysis of $M$. brevicollis, a unicellular choanoflagellate that possesses a PTK signalling system [70], brought a big surprise since the numbers of PTKs, PTPs and SH2 domains are comparable to or greater than those in mammals [6,100]. Numerous PTK, PTP, SH2 and PTB domain-containing proteins have been also identified in other pre-metazoan species $[196,197]$, challenging the simple notion of "expansion from yeast to man" in terms of the evolution of phosphotyrosine signalling. Since $M$. brevicollis contains a plethora of putative PTK toolkit proteins, many of which have no orthologs in humans $[6,100,196]$, it suggests that multiple evolutionary roads, which remain to be elucidated, may have been used to mix and match different pTyr signalling components in order to build the PTK signalling pathways and networks unique to a particular species. For example, bacteria may possess their own phosphotyrosine signalling systems as bacterial tyrosine kinases are found to be unrelated to eukaryotic PTKs $[198,199]$. Nevertheless, bacteria do not only rely on 


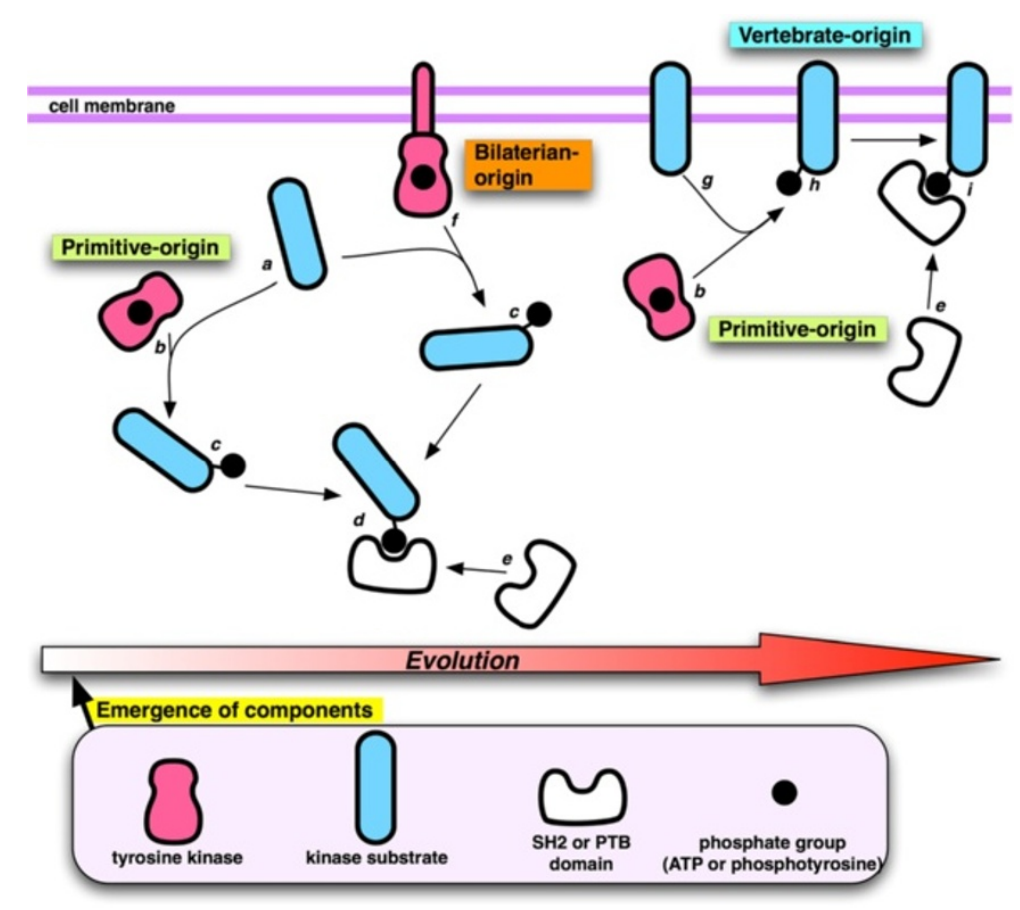

Figure 8 Evolution of the human PTK signalling circuit. A schematic depicting the evolution of the human PTK circuit, where $a, b, c, d$, and $e$ denote intracellular human circuits of a primitive origin, $a, f, c, d$, and e denote circuits with receptor tyrosine kinases and cytoplasmic substrates of bilaterian origin, and $g, b, h, i$ and $e$ denote vertebrate-origin circuits in which membrane-bound substrates are phosphorylated by cytoplasmic tyrosine kinases of a primitive origin in a tissue-specific manner. See reference [8] for more details.

their own repertoire of pTyr signalling components. Some pathogenic bacteria, for example the enteropathongenic Escherichia coli (EPEC) and Helicobacter pylori, are known to hijack pTyr signalling system components of their host by injecting a virulence factor into the host cell during infection [200,201]. The injected bacterial protein is then phosphorylated by a host PTK, and subsequently recruits $\mathrm{SH} 2$ domains of host proteins to rewire the host signalling network for the bacteria's benefit. The injected bacterial effectors have evolved to be readily phosphorylated by host PTKs, and to recruit a number of host $\mathrm{SH} 2$ domains after being phosphorylated $[201,202]$. For instance, EPEC injects a transmembrane effector protein Tir (translocated intimin receptor) to host cells upon infection. The cytoplasmic YDXV motif of Tir is then phosphorylated and recruits the $\mathrm{SH} 2$ domain of the adaptor protein NCK, which results in pathological actin reorganization [200,203]. It is noteworthy that a similar scenario is seen in the vaccinia virus. A tyrosine residue in the viral membrane protein named A36R is phosphorylated by host PTKs, and the viral protein subsequently recruits the NCK and Grb2 $\mathrm{SH} 2$ domains to manipulate downstream actin regulation of the host cell $[204,205]$. Intervention of pTyr-mediated host-pathogen interactions could be a novel therapeutic strategy, if sufficiently selective agents can be developed.

\section{Conclusions}

Much of what has been learnt in past decades about pTyr reader domains, their interactions and the networks that they serve can now be utilised and also warrants further exploration into several directions. Firstly, we need to make an effort to put more 'puzzle pieces' together to start seeing a more complete picture. This includes analysing in much more detail how the compartmentalisation of $\mathrm{pTyr}$ writers and readers, i.e. the architecture of the pTyr signalling machinery, generates highly specific signals in vivo. Protein modification reader domains should also be useful in a range of clinical settings, for example for molecular diagnoses and monitoring, but this potential remains untapped in clinical routine settings. As demonstrated for the $\mathrm{SH} 2$ domains, e.g., specificity-switching mutants or affinityenhanced "pTyr superbinders" $[40,61,63]$, engineering of pTyr-binding domains may yield protein-based reagents with desired specificities and affinities towards tyrosine phosphorylated targets, which may provide an array of novel agents for research and clinical purposes. Furthermore, we are just beginning to realise that at least some protein modification reader domains have the capacity to decipher combinations of modifications rather than recognising just single site changes, and further research in this area promises to provide additional clues 
to understanding the elegant ways in which cells manage to read and process a huge number of incoming signals and to translate them into a wide spectrum of biochemical and biological responses. Hence, typical and atypical pTyr reader domains should be considered to be 'old dogs up to new tricks' which we are just starting to grasp.

\section{Competing interests}

The authors declare that they have no competing interests.

\section{Authors' contributions}

RJ and TK drafted the first version of the manuscript. All authors edited and approved the final version.

\section{Acknowledgements}

Work from the Li laboratory was supported by grants from the Canadian Cancer Society, Canadian Institute of Health Research and Genome Canada. SSL holds a Canada Research Chair in Functional Genomics and Cellular Proteomics. SMF acknowledges funding by the Breast Cancer Campaign (UK) and the EU FP7 programme. We apologize to those whose work is relevant to this review but who are not cited because of space considerations or ou oversight.

\section{Author details}

'Department of Biochemistry and the Siebens-Drake Medical Research Institute, Schulich School of Medicine and Dentistry, University of Western Ontario, London, Ontario N6A 5C1, Canada. ${ }^{2}$ Biological Systems Architecture Group, Weatherall Institute of Molecular Medicine, Department of Oncology, University of Oxford, John Radcliffe Hospital, Headley Way, Oxford OX3 9DS, UK.

Received: 13 August 2012 Accepted: 9 October 2012

Published: 7 November 2012

\section{References}

1. Seet BT, Dikic I, Zhou MM, Pawson T: Reading protein modifications with interaction domains. Nat Rev Mol Cell Biol 2006, 7:473-483.

2. Lahiry P, Torkamani A, Schork NJ, Hegele RA: Kinase mutations in human disease: interpreting genotype-phenotype relationships. Nat Rev Genet 2010, 11:60-74.

3. Hunter T: Tyrosine phosphorylation: thirty years and counting. Curr Opin Cell Biol 2009, 21:140-146.

4. Jin J, Xie X, Chen C, Park JG, Stark C, James DA, Olhovsky M, Linding R, Mao Y, Pawson T: Eukaryotic protein domains as functional units of cellular evolution. Sci Signal 2009, 2:ra76.

5. Pawson T, Nash P: Assembly of cell regulatory systems through protein interaction domains. Science 2003, 300:445-452.

6. Pincus D, Ivica L, Peer B, Lim WA: Evolution of the phospho-tyrosine signaling machinery in premetazoan lineages. Proc Natl Acad Sci U S A 2008, 105:9680-9684

7. Lim WA, Pawson T: Phosphotyrosine signaling: evolving a new cellular communication system. Cell 2010, 142:661-667.

8. Li L, Tibiche C, Fu C, Kaneko T, Moran MF, Schiller MR, Li SS, Wang E: The human phosphotyrosine signalling network: Evolution and hotspots of hijacking in cancer. Genome Res 2012, 22:1222-1230.

9. Manning G, Whyte DB, Martinez R, Hunter T, Sudarsanam S: The protein kinase complement of the human genome. Science 2002, 298:1912-1934.

10. Liu BA, Jablonowski K, Raina M, Arce M, Pawson T, Nash PD: The human and mouse complement of $\mathrm{SH} 2$ domain proteins-establishing the boundaries of phosphotyrosine signalling. Mol Cell 2006, 22:851-868.

11. Liu BA, Shah E, Jablonowski K, Stergachis A, Engelmann B, Nash PD: The $\mathrm{SH} 2$ domain-containing proteins in 21 species establish the provenance and scope of phosphotyrosine signalling in eukaryotes. Sci Signal 2011, 4:ra83.

12. Liu BA, Engelmann BW, Nash PD: The Language of SH2 Domain Interactions Defines Phosphotyrosine-Mediated Signal Transduction. FEBS Lett 2012, 586:2597.
13. Tan CS, Bodenmiller B, Pasculescu A, Jovanovic M, Hengartner MO, Jorgensen C, Bader GD, Aebersold R, Pawson T, Linding R: Comparative analysis reveals conserved protein phosphorylation networks implicated in multiple diseases. Sci Signal 2009, 2:ra39.

14. Lemmon MA, Schlessinger J: Cell Signaling by Receptor Tyrosine Kinases. Cell 2010, 141:1117-1134

15. Pawson T, Kofler M: Kinome signalling through regulated protein-protein interactions in normal and cancer cells. Curr Opin Cell Biol 2009, 21:147-153.

16. Filippakopoulos $\mathrm{P}$, Muller S, Knapp S: SH2 domains: modulators of nonreceptor tyrosine kinase activity. Curr Opin Struct Biol 2009, 19:643-649

17. Mayer BJ: Perspective: Dynamics of receptor tyrosine kinase signalling complexes. FEBS Lett 2012, 586:2575-2579.

18. Songyang Z, Carraway IKL, Eck MJ, et al: Catalytic specificity of proteintyrosine kinase is critical for selective signalling. Nature 1995, 373:536-539.

19. Songyang Z, Cantley LC: Recognition and specificity in protein tyrosine kinase-mediated signalling. Trends Biochem Sci 1995, 20:470-475.

20. Huang H, Li L, Wu C, Schibli D, Colwill K, Ma S, Li C, Roy P, Ho K, Songyang Z, et al: Defining the specificity space of the human SRC homology 2 domain. Mol Cell Proteomics 2008, 7:768-784.

21. Miller ML, Jensen L, Diella F, Jorgensen C, Tinti M, Li L, Hsiung M, Parker SA, Bordeaux J, Sicheritz-Ponten T, et al: Linear motif atlas for phosphorylation-dependent signalling. Sci Signal 2008, 1:ra2.

22. Wavreille AS, Garaud M, Zhang Y, Pei D: Defining SH2 domain and PTP specificity by screening combinatorial peptide libraries. Methods 2007, 42:207-219

23. Wolf-Yadlin A, Sevecka M, MacBeath G: Dissecting protein function and signalling using protein microarrays. Curr Opin Chem Biol 2009, 13:398-405.

24. Scott JD, Pawson T: Cell signalling in space and time: where proteins come together and when they're apart. Science 2009, 326:1220-1224.

25. Bhattacharya R, et al: Domains, Motifs, and Scaffolds: The Role of Modular Interactions in the Evolution and Wiring of Cell Signaling Circuits. Annu Rev Biochem 2006, 75:655-680.

26. Sadowski I, Stone JC, Pawson T: A noncatalytic domain conserved among cytoplasmic protein-tyrosine kinases modifies the kinase function and transforming activity of Fujinami sarcoma virus P130gag-fps. Mol Cell Biol 1986, 6:4396-4408.

27. Pawson T: Specificity in Signal Transduction: From Phosphotyrosine-SH2 Domain Interactions to Complex Cellular Systems. Cell 2004, 116:191-203.

28. Mayer BJ, Hamaguchi M, Hanafusa H: A novel viral oncogene with structural similarity to phospholipase C. Nature 1988, 332:272-275.

29. Anderson D, Koch CA, Grey L, Ellis C, Moran MF, Pawson T: Binding of SH2 domains of phospholipase C gamma 1, GAP, and Src to activated growth factor receptors. Science 1990, 250:979-982.

30. Pawson T, Gish GD: SH2 and SH3 domains: from structure to function. Cell 1992, 71:359-362.

31. Matsuda M, Mayer BJ, Fukui Y, Hanafusa H: Binding of transforming protein, P47gag-crk, to a broad range of phosphotyrosine-containing proteins. Science 1990, 248:1537-1539.

32. Matsuda M, Mayer BJ, Hanafusa H: Identification of domains of the v-crk oncogene product sufficient for association with phosphotyrosinecontaining proteins. Mol Cell Biol 1991, 11:1607-1613.

33. Mayer BJ, Jackson PK, Baltimore D: The noncatalytic src homology region 2 segment of abl tyrosine kinase binds to tyrosine-phosphorylated cellular proteins with high affinity. Proc Natl Acad Sci U S A 1991, 88:627-631

34. Muller AJ, Pendergast AM, Havlik MH, Puil L, Pawson T, Witte ON: A limited set of $\mathrm{SH} 2$ domains binds $\mathrm{BCR}$ through a high-affinity phosphotyrosineindependent interaction. Mol Cell Biol 1992, 12:5087-5093.

35. Moran MF, Koch CA, Anderson D, Ellis C, England L, Martin GS, Pawson T: Src homology region 2 domains direct protein-protein interactions in signal transduction. Proc Natl Acad Sci U S A 1990, 87:8622-8626.

36. Filippakopoulos P, Kofler M, Hantschel O, Gish GD, Grebien F, Salah E, Neudecker P, Kay LE, Turk BE, Superti-Furga G, et al: Structural coupling of SH2-kinase domains links Fes and Abl substrate recognition and kinase activation. Cell 2008, 134:793-803.

37. Heldin $\mathrm{CH}: \mathrm{SH} 2$ domains: elements that control protein interactions during signal transduction. Trends Biochem Sci 1991, 16:450-452.

38. Waksman G, Kominos D, Robertson SC, Pant N, Baltimore D, Birge RB, Cowburn D, Hanafusa H, Mayer BJ, Overduin M, et al: Crystal structure of 
the phosphotyrosine recognition domain $\mathrm{SH} 2$ of $\mathrm{v}$-src complexed with tyrosine-phosphorylated peptides. Nature 1992, 358:646-653.

39. Waksman G, Shoelson SE, Pant N, Cowburn D, Kuriyan J: Binding of a high affinity phosphotyrosyl peptide to the $\mathrm{Src} \mathrm{SH} 2$ domain: crystal structures of the complexed and peptide-free forms. Cell 1993, 72:779-790.

40. Kaneko T, Huang H, Zhao B, Li L, Liu H, Voss CK, Wu C, Schiller MR, Li SS: Loops govern $\mathrm{SH} 2$ domain specificity by controlling access to binding pockets. Sci Signal 2010, 3:ra34.

41. Waksman G, Kuriyan J: Structure and specificity of the SH2 domain. Cell 2004, S116:S45-S48.

42. Feller SM, Ren R, Hanafusa H, Baltimore D: SH2 and SH3 domains as molecular adhesives: the interactions of Crk and Abl. Trends Biochem Sci 1994, 19:453-458.

43. Meng $\mathrm{W}$, et al: Structure of the amino-terminal domain of $\mathrm{Cbl}$ complexed to its binding site on ZAP-70 kinase. Nature 1999, 398:84-90.

44. Mallis RJ, Brazin KN, Fulton DB, Andreotti AH: Structural characterization of a proline-driven conformational switch within the Itk SH2 domain. Nat Struct Biol 2002, 9:900-905.

45. Severin A, Joseph RE, Boyken S, Fulton DB, Andreotti AH: Proline isomerization preorganizes the Itk SH2 domain for binding to the Itk SH3 domain. J Mol Biol 2009, 387:726-743.

46. Joseph RE, Ginder ND, Hoy JA, Nix JC, Fulton DB, Honzatko RB, Andreotti AH: Structure of the interleukin-2 tyrosine kinase Src homology 2 domain; comparison between X-ray and NMR-derived structures. Acto crystallographica Section F 2012, 68:145-153.

47. Donaldson LW, Gish G, Pawson T, Kay LE, Forman-Kay JD: Structure of a regulatory complex involving the $\mathrm{Abl} \mathrm{SH3}$ domain, the $\mathrm{Crk} \mathrm{SH} 2$ domain and a Crk-derived phosphopeptide. Proc Natl Acad Sci U S A 2002, 99:14053-14058.

48. Close D, Johnson SJ, Sdano MA, McDonald SM, Robinson H, Formosa T, Hill CP: Crystal structures of the S. cerevisiae Spt6 core and C-terminal tandem SH2 domain. J Mol Biol 2011, 408:697-713.

49. Sun M, Lariviere L, Dengl S, Mayer A, Cramer P: A tandem SH2 domain in transcription elongation factor Spt6 binds the phosphorylated RNA polymerase II C-terminal repeat domain (CTD). J Biol Chem 2010, 285:41597-41603.

50. Liu J, Zhang J, Gong Q, Xiong P, Huang H, Wu B, Lu G, Wu J, Shi Y: Solution structure of tandem $\mathrm{SH} 2$ domains from Spt6 protein and their binding to the phosphorylated RNA polymerase II C-terminal domain. J Biol Chem 2011, 286:29218-29226.

51. Diebold ML, Loeliger E, Koch M, Winston F, Cavarelli J, Romier C: Noncanonical tandem $\mathrm{SH} 2$ enables interaction of elongation factor Spt6 with RNA polymerase II. J Biol Chem 2010, 285:38389-38398.

52. Yoh SM, Cho H, Pickle L, Evans RM, Jones KA: The Spt6 SH2 domain binds Ser2-P RNAPII to direct Iws1-dependent mRNA splicing and export. Genes Dev 2007, 21:160-174.

53. Songyang Z, Shoelson SE, Chaudhuri M, Gish G, Pawson T, Haser WG, King F, Roberts T, Ratnofsky S, Lechleider RJ, et al: $\mathrm{SH} 2$ domains recognize specific phosphopeptide sequences. Cell 1993, 72:767-778.

54. Songyang Z, Shoelson SE, McGlade J, Olivier P, Pawson T, Bustelo XR, Barbacid M, Sabe H, Hanafusa $H$, Yi T, et al: Specific motifs recognized by the SH2 domains of Csk, 3BP2, fps/fes, GRB-2, HCP, SHC, Syk, and Vav. Mol Cell Biol 1994, 14:2777-2785.

55. Songyang Z, Cantley LC: ZIP codes for delivering SH2 domains. Cell 2004, S116:S41-S43

56. Ladbury JE, Arold ST: Energetics of Src homology domain interactions in receptor tyrosine kinase-mediated signalling. Methods Enzymol 2011 488:147-183.

57. Jones RB, Gordus A, Krall JA, MacBeath G: A quantitative protein interaction network for the ErbB receptors using protein microarrays. Nature 2006, 439:168-174.

58. Kaushansky A, Gordus A, Chang B, Rush J, MacBeath G: A quantitative study of the recruitment potential of all intracellular tyrosine residues on EGFR, FGFR1 and IGF1R. Mol Biosyst 2008, 4:643-653.

59. Kaushansky A, Gordus A, Budnik BA, Lane WS, Rush J, MacBeath G: Systemwide investigation of ErbB4 reveals 19 sites of Tyr phosphorylation that are unusually selective in their recruitment properties. Chem Biol 2008, 15:808-817.

60. Hause RJ Jr, Leung KK, Barkinge JL, Ciaccio MF, Chuu CP, Jones RB: Comprehensive Binary Interaction Mapping of SH2 Domains via
Fluorescence Polarization Reveals Novel Functional Diversification of ErbB Receptors. PLoS One 2012, 7:e44471.

61. Kaneko T, Huang H, Cao X, Li X, Li C, Voss C, Sidhu SS, Li SS: Superbinder SH2 Domains Act as Antagonists of Cell Signaling. Sci Signal 2012, 5:ra68.

62. Waksman G, Kumaran S, Lubman O: SH2 domains: role, structure and implications for molecular medicine. Expert Rev Mol Med 2004, 6:1-18.

63. Marengere LE, Songyang Z, Gish GD, Schaller MD, Parsons JT, Stern M Cantley LC, Pawson T: SH2 domain specificity and activity modified by a single residue. Nature 1994, 369:502-505.

64. Kaneko T, Sidhu SS, Li SS: Evolving specificity from variability for protein interaction domains. Trends Biochem Sci 2011, 36:183-190.

65. Liu BA, Jablonowski K, Shah EE, Engelmann BW, Jones RB, Nash PD: SH2 domains recognize contextual peptide sequence information to determine selectivity. Mol Cell Proteomics 2010, 9:2391-2404.

66. Rodriguez M, Li SS, Harper JW, Songyang Z: An oriented peptide array library (OPAL) strategy to study protein-protein interactions. J Biol Chem 2004, 279:8802-8807.

67. Egloff S, Murphy S: Cracking the RNA polymerase II CTD code. Trends Genet 2008, 24:280-288.

68. Hsin JP, Sheth A, Manley JL: RNAP II CTD phosphorylated on threonine-4 is required for histone mRNA 3' end processing. Science 2011, 334:683-686.

69. Dengl S, Mayer A, Sun M, Cramer P: Structure and in vivo requirement of the yeast Spt6 SH2 domain. J Mol Biol 2009, 389:211-225.

70. King N, Hittinger CT, Carroll SB: Evolution of key cell signalling and adhesion protein families predates animal origins. Science 2003, 301:361-363.

71. Raffel GD, Parmar K, Rosenberg N: In vivo association of v-Abl with Shc mediated by a non-phosphotyrosine-dependent SH2 interaction. J Biol Chem 1996, 271:4640-4645.

72. Dutartre $\mathrm{H}$, Harris $\mathrm{M}$, Olive $\mathrm{D}$, Collette $\mathrm{Y}$ : The human immunodeficiency virus type 1 Nef protein binds the Src-related tyrosine kinase Lck SH2 domain through a novel phosphotyrosine independent mechanism. Virology 1998, 247:200-211

73. Hwang PM, Li C, Morra M, Lillywhite J, Muhandiram DR, Gertler F, Terhorst C, Kay LE, Pawson T, Forman-Kay JD, Li S-C: A "three-pronged" binding mechanism for the SAP/SH2D1A SH2 domain: structural basis and relevance to the XLP syndrome. EMBO J 2002, 21:314-323.

74. Liao Y-C, Si L, deVere White RW, Lo SH: The phosphotyrosine-independent interaction of DLC-1 and the $\mathrm{SH} 2$ domain of cten regulates focal adhesion localization and growth suppression activity of DLC-1. J Cell Biol 2007, 176:43-49.

75. Qian X, Li G, Asmussen HK, Asnaghi L, Vass WC, Braverman R, Yamada KM, Popescu NC, Papageorge AG, Lowy DR: Oncogenic inhibition by a deleted in liver cancer gene requires cooperation between tensin binding and Rho-specific GTPase-activating protein activities. Proc Natl Acad Sci U S A 2007, 104:9012-9017.

76. Bae JH, Lew ED, Yuzawa S, Tome F, Lax I, Schlessinger J: The selectivity of receptor tyrosine kinase signalling is controlled by a secondary $\mathrm{SH} 2$ domain binding site. Cell 2009, 138:514-524.

77. Min L, Joseph RE, Fulton DB, Andreotti AH: Itk tyrosine kinase substrate docking is mediated by a nonclassical $\mathrm{SH} 2$ domain surface of PLCgamma1. Proc Natl Acad Sci U S A 2009, 106:21143-21148.

78. Dai K, Liao S, Zhang J, Zhang X, Tu X: Solution structure of tensin2 SH2 domain and its phosphotyrosine-independent interaction with DLC-1. PLoS One 2011, 6:e21965.

79. Poy F, et al: Crystal Structures of the XLP Protein SAP Reveal a Class of SH2 Domains with Extended, Phosphotyrosine-Independent Sequence Recognition. Mol Cell 1999, 4:555-561.

80. Fang $Y$, Johnson LM, Mahon ES, Anderson DH: Two phosphorylationindependent sites on the p85 SH2 domains bind A-Raf kinase. Biochem Biophys Res Commun 2002, 290:1267-1274.

81. Robinson DR, et al: The protein tyrosine kinase family of the human genome. Oncogene 2000, 19:5548-5557.

82. Mayer BJ, Hirai H, Sakai R: Evidence that SH2 domains promote processive phosphorylation by protein-tyrosine kinases. Current biology: CB 1995, 5:296-305.

83. Colicelli J: ABL tyrosine kinases: evolution of function, regulation, and specificity. Sci Signal 2010, 3:re6.

84. Akiva E, Friedlander G, Itzhaki Z, Margalit H: A dynamic view of domainmotif interactions. PLoS Comput Biol 2012, 8:e1002341. 
85. Uhlik MT, Temple B, Bencharit S, Kimple AJ, Siderovski DP, Johnson GL: Structural and evolutionary division of phosphotyrosine binding (PTB) domains. J Mol Biol 2005, 345:1-20.

86. Pei D, Lorenz U, Klingmuller U, Neel BG, Walsh CT: Intramolecular regulation of protein tyrosine phosphatase SH-PTP1: a new function for Src homology 2 domains. Biochemistry 1994, 33:15483-15493.

87. Hof P, Pluskey S, et al: Crystal Structure of the Tyrosine Phosphatase SHP-2. Cell 1998, 92:441-450

88. Yang J, Liu L, He D, Song X, Liang X, Zhao Z, Zhou GW: Crystal structure of human protein-tyrosine phosphatase SHP-1. J Biol Chem 2003, 278:6516-6520.

89. Wang W, Liu L, Song X, Mo Y, Komma C, Bellamy HD, Zhao ZJ, Zhou GW: Crystal structure of human protein tyrosine phosphatase SHP-1 in the open conformation. J Cell Biochem 2011, 112:2062-2071.

90. Zhang $Y$, Jinjin Z, Chunhua $Y$, Ryan LH, In-Hee P, Chenglong L, Charles B, Pei D: Simultaneous Binding of Two Peptidyl Ligands by a Src Homology 2 Domain. Biochemistry 2011, 50:7637-7646.

91. Kesti T, Ruppelt A, Wang J-H, Liss M, Wagner R, Taskén K, Saksela K: Reciprocal regulation of $\mathrm{SH} 3$ and $\mathrm{SH} 2$ domain binding via tyrosine phosphorylation of a common site in CD3epsilon. J Immunol 2007, 179:878-885.

92. Aitio O, Hellman M, Kesti T, Kleino I, Samuilova O, Pääkkönen $K$, Tossavainen H, Saksela K, Permi P: Structural basis of PxxDY motif recognition in SH3 binding. J Mol Biol 2008, 382:167-178.

93. Takeuchi K, Yang H, Ng E, Park S-y, Sun Z-YJ, Reinherz EL, Wagner G: Structural and functional evidence that Nck interaction with CD3epsilon regulates T-cell receptor activity. J Mol Biol 2008, 380:704-716.

94. Wang Z, Sandiford S, Wu C, Li SS: Numb regulates cell-cell adhesion and polarity in response to tyrosine kinase signalling. EMBO J 2009, 28:2360-2373

95. Fujita Y, Krause G, Scheffner M, Zechner D, Leddy HE, Behrens J, Sommer T, Birchmeier W: Hakai, a c-Cbl-like protein, ubiquitinates and induces endocytosis of the E-cadherin complex. Nat Cell Biol 2002, 4:222-231.

96. Mukherjee M, Chow SY, Yusoff P, Seetharaman J, Ng C, Sinniah S, Koh XW, Asgar NF, Li D, Yim D, et al: Structure of a novel phosphotyrosine-binding domain in Hakai that targets E-cadherin. EMBO J 2012, 31:1308-1319.

97. Blaikie $P$, Immanuel D, Wu J, Li N, Yajnik V, Margolis B: A region in Shc distinct from the $\mathrm{SH} 2$ domain can bind tyrosine-phosphorylated growth factor receptors. J Biol Chem 1994, 269:32031-32034.

98. Kavanaugh WM, Williams LT: An alternative to $\mathrm{SH} 2$ domains for binding tyrosine-phosphorylated proteins. Science 1994, 266:1862-1865.

99. Forman-Kay JD, Pawson T: Diversity in protein recognition by PTB domains. Curr Opin Struct Biol 1999, 9:690-695.

100. Manning G, Young SL, Miller WT, Zhai Y: The protist, Monosiga brevicollis, has a tyrosine kinase signalling network more elaborate and diverse than found in any known metazoan. Proc Natl Acad Sci U S A 2008 105:9674-9679.

101. Yaffe M: Phosphotyrosine-Binding Domains in Signal Transduction. Nat Rev Mol Cell Biol 2002, 3:177-186.

102. Prieto-Echague V, Chan PM, Craddock BP, Manser E, Miller WT: PTB domaindirected substrate targeting in a tyrosine kinase from the unicellular choanoflagellate Monosiga brevicollis. PLoS One 2011, 6:e19296.

103. Lemmon MA: Membrane recognition by phospholipid-binding domains. Nat Rev Mol Cell Biol 2008, 9:99-111.

104. Li SC, Zwahlen C, Vincent SJ, McGlade CJ, Kay LE, Pawson T, Forman-Kay JD: Structure of a Numb PTB domain-peptide complex suggests a basis for diverse binding specificity. NatStruct Biol 1998, 5:1075-1083.

105. Zhou MM, Huang B, Olejniczak ET, Meadows RP, Shuker SB, Miyazaki M, Trub T, Shoelson SE, Fesik SW: Structural basis for IL-4 receptor phosphopeptide recognition by the IRS-1 PTB domain. Nat Struct Biol 1996, 3:388-393

106. Zhou MM, Ravichandran KS, Olejniczak EF, Petros AM, Meadows RP, Sattler M, et al: Structure and ligand recognition of the phosphotyrosine binding domain of Shc. Nature 1995, 378:584-592.

107. Dhe-Paganon, Ottinger EA, Nolte RT, Eck MJ, Shoelsen SE: Crystal structure of the pleckstrin homology-phosphotyrosine binding (PH-PTB) targeting region of insulin receptor substrate 1. Proc Natl Acad Sci U S A 1999, 96:8378-8383.

108. Stolt PC, Jeon H, Song HK, Herz J, Eck MJ, Blacklow SC: Origins of Peptide Selectivity and Phosphoinositide Binding Revealed by Structures of Disabled-1 PTB Domain Complexes. Structure 2003, 11:569-579.
109. Yun M, Keshvara L, Park CG, Zhang YM, Dickerson JB, Zheng J, Rock CO, Curran T, Park HW: Crystal structures of the Dab homology domains of mouse disabled 1 and 2. J Biol Chem 2003, 278:36572-36581.

110. DiNitto JP, Lambright DG: Membrane and juxtamembrane targeting by PH and PTB domains. Biochim Biophys Acta 2006, 1761:850-867.

111. Zwahlen C, Li SC, Kay LE, Pawson T, Forman-Kay JD: Multiple modes of peptide recognition by the PTB domain of the cell fate determinant Numb. EMBO J 2000, 19:1505-1515.

112. Chen L, Liu C, Ko FC, Xu N, Ng IO, Yam JW, Zhu G: Solution structure of the PTB domain of human Tensin2 in complex with deleted in liver cancer 1 (DLC1) peptide reveals a novel peptide binding mode. J Biol Chem 2012, 287:26104-26114.

113. Schulze WX, Deng L, Mann M: Phosphotyrosine interactome of the ErbBreceptor kinase family. Mol Syst Biol 2005, 1:13.

114. Smith MJ, Hardy WR, Murphy JM, Jones N, Pawson T: Screening for PTB domain binding partners and ligand specificity using proteome-derived NPXY peptide arrays. Mol Cell Biol 2006, 26:8461-8474.

115. Rameh LE, Arvidsson A-K, Carraway IKL, Couvillon AD, Rathbun G, Cromptoni A, VanRenterghem B, Czech MP, Ravichandran KS, Burakoff SJ, et al: A comparative analysis of the phosphoinositide binding specificity of pleckstrin homology domains. J Biol Chem 1997, 272:22059-22066.

116. Guo $M$, Jan $L Y$, Jan YN: Control of daughter cell fates during asymmetric division:interaction of Numb and Notch. Neuron 1996, 17:27-41.

117. Qin H, Percival-Smith A, Li C, Jia CY, Gloor G, Li SS: A novel transmembrane protein recruits numb to the plasma membrane during asymmetric cell division. J Biol Chem 2004, 279:11304-11312

118. Nie J, Li SS, McGlade CJ: A novel PTB-PDZ domain interaction mediates isoform-specific ubiquitylation of mammalian Numb. J Biol Chem 2004 279:20807-20815.

119. Wang Z, Li SC: Numb: A new player in EMT. Cell Adh Migr 2010, 4:176-179.

120. Alonso A, Sasin J, Bottini N, Friedberg I, Friedberg I, Osterman A, et al: Protein tyrosine phosphatases in the human genome. Cell 2004 117:699-711.

121. Haynie DT, Ponting CP: The N-terminal domains of tensin and auxilin are phosphatase homologues. Protein Sci 1996, 5:2643-2646.

122. Lo SH: Tensin. Int J Biochem Cell Biol 2004, 36:31-34.

123. Song MS, Salmena L, Pandolfi PP: The functions and regulation of the PTEN tumour suppressor. Nat Rev Mol Cell Biol 2012, 13:283-296.

124. Cao X, Voss C, Zhao B, Kaneko T, Li SSC: Differential regulation of the activity of deleted in liver cancer 1 (DLC1) by tensins controls cell migration and transformation. Proc Natl Acad Sci U S A 2012, 109:1455-1460.

125. Qian X, Li G, Vass WC, Papageorge A, Walker RC, Asnaghi L, Steinbach PJ, Tosato G, Hunter K, Lowy DR: The Tensin-3 protein, including its $\mathrm{SH} 2$ domain, is phosphorylated by Src and contributes to tumorigenesis and metastasis. Cancer Cell 2009, 16:246-258.

126. McCleverty CJ, Lin DC, Liddington RC: Structure of the PTB domain of tensin 1 and a model for its recruitment to fibrillar adhesions. Protein $\mathrm{SCi}$ 2007, 16:1223-1229.

127. Calderwood DA, Fujioka Y, de Pereda JM, Garcia-Alvarez B, Nakamoto T, Margolis B, McGlade CJ, Liddington RC, Ginsberg MH: Integrin beta cytoplasmic domain interactions with phosphotyrosine-binding domains: a structural prototype for diversity in integrin signalling. Proc Natl Acad Sci U S A 2003, 100:2272-2277.

128. Figueroa A, Fujita Y, Gorospe M: Hacking RNA: Hakai promotes tumorigenesis by enhancing the RNA-binding function of PSF. Cell Cycle 2009, 8:3648-3651.

129. Rodriguez-Rigueiro T, Valladares-Ayerbes M, Haz-Conde M, Aparicio LA Figueroa A: Hakai reduces cell-substratum adhesion and increases epithelial cell invasion.BMC Cancer 2011, 11:474.

130. Katoh K, Asimenos G, Toh H: Multiple alignment of DNA sequences with MAFFT. Methods Mol Biol 2009, 537:39-64

131. Mayer BJ, Ren R, Clark KL, Baltimore D: A putative modular domain present in diverse signalling molecules. Cell 1993, 73:620-630

132. Haslam RJ, Koide HB, Hemmings BA: Pleckstrin domain homology. Nature 1993, 363:309-310.

133. Lemmon MA, Ferguson K: Signal-dependent membrane targeting by pleckstrin homology (PH) domains. Biochem J 2000, 350:1-18.

134. Touhara K, Inglese J, Pitcher JA, Shaw G, Lefkowitz RJ: Binding of G-protein Beta-gamma subunits to pleckstrin homology domains. J Biol Chem 1994 269:10217-10220 
135. Wang DS, Shaw R, Winkelmann JC, Shaw G: Binding of PH domains of beta-adrenergic receptor kinase and beta-spectrin to WD40/betatransducin repeat containing regions of the beta-subunit of trimeric G-proteins. Biochem Biophys Res Commun 1994, 203:29-35.

136. Yao L, Suzuki H, Ozawa K, Deng J, Lehel C, Fukamachi H, Anderson WB, Kawakami $Y$, Kawakami $T$ : Interactions between protein kinase $C$ and pleckstrin homology domains. Inhibition by phosphatidylinositol 4,5-bisphosphate and phorbol 12-myristate 13-acetate. J Biol Chem 1997, 272:13033-13039.

137. Liu L, Makowske M: Phosphotyrosine protein of molecular mass $30 \mathrm{kDa}$ binds specifically to the positively charged region of the pleckstrin N-terminal pleckstrin homology domain. Biochem J 1999, 342:423-430.

138. Morishige M, Hashimoto S, Ogawa E, Toda Y, Kotani H, Hirose M, Wei S, Hashimoto A, Yamada A, Yano H, et al: GEP100 links epidermal growth factor receptor signalling to Arf6 activation to induce breast cancer invasion. Nat Cell Biol 2008, 10:85-92.

139. Foley J, Nickerson NK, Nam S, Allen KT, Gilmore JL, Nephew KP, Riese DJ II: EGFR signalling in breast cancer: Bad to the bone. Semin Cell Dev Biol 2010, 21:950-961.

140. Shao H, Cheng HY, Cook RG, et al: Identification and Characterization of Signal Transducer and Activator of Transcription 3 Recruitment sites within the Epidermal Growth Factor Receptor. Cancer Res 2003, 63:3923-3930

141. Sabe H, Hashimoto S, Morishige M, Ogawa E, Hashimoto A, Nam JM, Miura K, Yano H, Onodera Y: The EGFR-GEP100-Arf6-AMAP1 signalling pathway specific to breast cancer invasion and metastasis. Traffic 2009, 10:982-993.

142. Valderrama F, Ridley AJ: Getting invasive with GEP100 and Arf6. Nat Cell Biol 2008, 10:16-18.

143. Zhang D, Aravind L: Identification of novel families and classification of the $\mathrm{C} 2$ domain superfamily elucidate the origin and evolution of membrane targeting activities in eukaryotes. Gene 2010, 469:18-30.

144. Cho W, Stahelin RV: Membrane binding and subcellular targeting of C2 domains. Biochim BiophysActa 2006, 1761:838-849.

145. Benes CH, Wu N, Elia AE, Dharia T, Cantley LC, Soltoff SP: The C2 domain of PKCdelta is a phosphotyrosine binding domain. Cell 2005, 121:271-280.

146. Sondermann H, Kuriyan J: C2 can do it, too. Cell 2005, 121:158-160.

147. Wortmann A, He Y, Deryugina El, Quigley JP, Hooper JD: The cell surface glycoprotein CDCP1 in cancer-insights, opportunities, and challenges. IUBMB Life 2009, 61:723-730.

148. Stahelin RV, Kong KF, Raha S, Tian W, Melowic HR, Ward KE, Murray D, Altman A, Cho W: Protein Kinase C $\theta$ C2 Domain Is a Phosphotyrosine Binding Module That Plays a Key Role in Its Activation. J Biol Chem 2012, 287:30518-30528.

149. Simister PC, Burton NM, Brady RL: Phosphotyrosine Recognition by the Raf Kinase Inhibitor Protein. Forum on Immunopathological Diseases and Therapeutics 2011, 2:59-70.

150. Christofk HR, Heiden MGV, Wu N, Asara JM, Cantley LC: Pyruvate kinase M2 is a phosphotyrosine binding protein. Nature 2008, 452:182-189.

151. Edwards A: Large-scale structural biology of the human proteome. Annu Rev Biochem 2009, 78:541-568.

152. Wishart MJ, Denu JM, Williams JA, Dixon JE: A Single Mutation Converts a Novel Phosphotyrosine Binding Domain into a Dual-specificity Phosphatase. J Biol Chem 1995, 270:26782-26785.

153. Wishart MJ, Dixon JE: Gathering STYX: phosphatase-like form predicts functions for unique protein-interaction domains. Trends Biochem Sci 1998, 23:302-306.

154. Tonks NK: Protein tyrosine phosphatases: from genes, to function, to disease. Nat Rev Mol Cell Biol 2006, 7:833-846.

155. Almo SC, Bonanno JB, Sauder JM, Emtage S, Dilorenzo TP, Malashkevich V, Wasserman SR, Swaminathan S, Eswaramoorthy S, Agarwal R, et al Structural genomics of protein phosphatases. J Struct Funct Genomics 2007, 8:121-140.

156. Tonks NK: Pseudophosphatases: grab and hold on. Cell 2009, 139:464-465.

157. Hinton SD, Myers MP, Roggero VR, Allison LA, Tonks NK: The pseudophosphatase MK-STYX interacts with G3BP and decreases stress granule formation. Biochem J 2010, 427:349-357.

158. Cheng KC, Klancer R, Singson A, Seydoux G: Regulation of MBK-2/DYRK by CDK-1 and the pseudophosphatases EGG-4 and EGG-5 during the oocyte-to-embryo transition. Cell 2009, 139:560-572.
159. Gingras MC, Zhang YL, Kharitidi D, Barr AJ, Knapp S, Tremblay ML, Pause A HD-PTP is a catalytically inactive tyrosine phosphatase due to a conserved divergence in its phosphatase domain. PLoS One 2009, 4:e5105.

160. Li J, Clifford Y, Danny L, Katrina P, Shikha B, Steven IW, Janusz P, Christa M, Linda R, Richard MC, et al: PTEN, a Putative Protein Tyrosine Phosphatase Gene Mutated in Human Brain, Breast,and Prostate Cancer. Science 1997 275:1943-1948

161. Guan R, Dai H, Harrison SC, Kirchhausen T: Structure of the PTEN-like region of auxilin, a detector of clathrin-coated vesicle budding. Structure 2010, 18:1191-1198.

162. Lee JO, Yang H, Georgescu MM, Di Cristofano A, Maehama T, Shi Y, Dixon JE, Pandolfi P, Pavletich NP: Crystal Structure of the PTEN Tumor Suppressor: Implications for Its Phosphoinositide Phosphatase Activity and Membrane Association. Cell 1999, 99:323-334.

163. Yeung K, Seitz T, Li S, Janosch P, McFerran B, Kaiser C, Fee F, Katsanakis KD, Rose DW, Mischak H, Sedivy JM, Kolch W: Suppression of Raf-1 kinase activity and MAP kinase signalling by RKIP. Nature 1999, 401:173-178.

164. Park S, Rath O, Beach S, Xiang X, Kelly SM, Luo Z, Kolch W, Yeung KC: Regulation of RKIP binding to the N-region of the Raf- 1 kinase. FEBS Lett 2006, 580:6405-6413.

165. Rath O, Park S, Tang HH, Banfield MJ, Brady RL, Lee YC, Dignam JD, Sedivy JM, Kolch W, Yeung KC: The RKIP (Raf-1 Kinase Inhibitor Protein) conserved pocket binds to the phosphorylated N-region of Raf-1 and inhibits the Raf1-mediated activated phosphorylation of MEK. Cell Signal 2008, 20:935-942.

166. Tavel L, Jaquillard L, Karsisiotis Al, Saab F, Jouvensal L, Brans A, Delmas AF, Schoentgen F, Cadene M, Damblon C: Ligand Binding Study of Human PEBP1/RKIP: Interaction with Nucleotides and Raf-1 Peptides Evidenced by NMR and Mass Spectrometry. PLoS One 2012, 7:e36187.

167. Christofk HR, Vander Heiden MG, Harris MH, Ramanathan A, Gerszten RE, Wei R, Fleming MD, Schreiber SL, Cantley LC: The M2 splice isoform of pyruvate kinase is important for cancer metabolism and tumour growth. Nature 2008, 452:230-234.

168. Mazurek S: Pyruvate kinase type M2: a key regulator of the metabolic budget system in tumor cells. Int J Biochem Cell Biol 2011, 43:969-980.

169. Dombrauckas JD, Santarsiero BD, Mesecar AD: Structural Basis for Tumor Pyruvate Kinase M2 Allosteric Regulation and Catalysis. Biochemistry 2005, 44:9417-9429.

170. Christofk HR, Wu N, Cantley LC, Asara JM: Proteomic screening method for phosphopeptide motif binding proteins using peptide libraries. J Proteome Res 2011, 10:4158-4164.

171. Martin GS: The hunting of the Src. Nat Rev Mol Cell Biol 2001, 2:467-475

172. Sawyer TK, Shakespeare WC, Wang Y, Sundaramoorthi R, Huang WS, Metcalf CA 3rd, Thomas M, Lawrence BM, Rozamus L, Noehre J, et al: Protein phosphorylation and signal transduction modulation: chemistry perspectives for small-molecule drug discovery. Med Chem 2005, 1:293-319.

173. Lappalainen I, Thusberg J, Shen B, Vihinen M: Genome wide analysis of pathogenic SH2 domain mutations. Proteins 2008, 72:779-792.

174. Hong Y, Chalkia D, Ko KD, Bhardwaj G, Chang GS, van Rossum DB, Patterson RL: Phylogenetic Profiles Reveal Structural and Functional Determinants of Lipid-binding. J Proteomics Bioinform 2009, 2:139-149.

175. Koskela HLM, Eldfors S, et al: Somatic STAT3 Mutations in Large Granular Lymphocytic Leukemia. N Engl J Med 2012, 366:1905-1913.

176. Giacomelli M, Tamassia N, Moratto D, Bertolini P, Ricci G, Bertulli C, Plebani A, Cassatella M, Bazzoni F, Badolato R: SH2-domain mutations in STAT3 in hyper-lgE syndrome patients result in impairment of IL-10 function. Eur J Immunol 2011, 41:3075-3084.

177. Machida K, Mayer BJ: The SH2 domain: versatile signalling module and pharmaceutical target. Biochim Biophys Acta 2005, 1747:1-25.

178. Lu XL, Cao X, Liu XY, Jiao BH: Recent progress of Src SH2 and SH3 inhibitors as anticancer agents. Curr Med Chem 2010, 17:1117-1124.

179. Grebien F, Hantschel O, Wojcik J, Kaupe I, Kovacic B, Wyrzucki AM, Gish GD Cerny-Reiterer S, Koide A, Beug H, Pawson T, Valent P, Koide S, SupertiFurga $\mathrm{G}$ et al: Targeting the SH2-Kinase Interface in Bcr-Abl Inhibits Leukemogenesis.Cell 2011, 147:306-319.

180. Bloom L, Calabro V: FN3: a new protein scaffold reaches the clinic. Drug Discov Today 2009, 14:949-955.

181. Wojcik J, Hantschel O, Grebien F, Kaupe I, Bennett KL, Barkinge J, Jones RB, Koide A, Superti-Furga G, Koide S: A potent and highly specific FN3 
monobody inhibitor of the Abl SH2 domain. Nat Struct Mol Biol 2010, 17:519-527.

182. Jadwin JA, Ogiue-lkeda M, Machida K: The application of modular protein domains in proteomics. FEBS Lett 2012, 586:2586.

183. Machida K, Mayer BJ, Nollau P: Profiling the global tyrosine phosphorylation state. Mol Cell Proteomics 2003, 2:215-233.

184. Dierck K, Machida K, Voigt A, Thimm J, Horstmann M, Fiedler W, Mayer BJ, Nollau P: Quantitative multiplexed profiling of cellular signalling networks using phosphotyrosine-specific DNA-tagged SH2 domains. Nat Methods 2006, 3:737-744

185. Machida K, Thompson CM, Dierck K, Jablonowski K, Karkkainen S, Liu B, Zhang H, Nash PD, Newman DK, Nollau P, et al: High-throughput phosphotyrosine profiling using SH2 domains. Mol Cell 2007, 26:899-915.

186. Dierck K, Machida K, Mayer BJ, Nollau P: Profiling the tyrosine phosphorylation state using SH2 domains. Methods Mol Biol 2009 527:131-155.

187. Machida K, Eschrich S, Li J, Bai Y, Koomen J, Mayer BJ, Haura EB: Characterizing tyrosine phosphorylation signalling in lung cancer using SH2 profiling. PLOS One 2010, 5:e13470.

188. Nagahara H, Vocero-Akbani AM, et al: Transduction of full-length TAT fusion proteins into mammalian cells: TAT-p27Kip1 induces cell migration. Nat Med 1998, 4:1449-1452.

189. Katterle Y, Brandt BH, Dowdy SF, Niggemann B, Zanker KS, Dittmar T: Antitumour effects of PLC-gamma1-(SH2)2-TAT fusion proteins on EGFR/ c-erbB-2-positive breast cancer cells. Br J Cancer 2004, 90:230-235.

190. Saito Y, Furukawa T, Arano Y, Fujibayashi Y, Saga T: Fusion protein based on Grb2-SH2 domain for cancer therapy. Biochem Biophys Res Commun 2010, 399:262-267.

191. Saito Y, Furukawa T, Arano Y, Fujibayashi Y, Saga T: Basic study on SH2 domain of Grb2 as a molecular probe for detection of RTK activation. Int J Oncol 2010, 37:281-287.

192. Wang Y, Botvinick EL, et al: Visualizing the mechanicalactivation of Src. Nature 2005, 434:1040-1045.

193. Antczak C, Bermingham A, et al: Domain-Based Biosensor Assay to Screen for Epidermal Growth Factor Receptor Modulators in Live Cells. Assay Drug Dev Technol 2012, 10:24-36.

194. Amit I, Wides R, Yarden Y: Evolvable signalling networks of receptor tyrosine kinases: relevance of robustness to malignancy and to cancer therapy. Mol Syst Biol 2007, 3:151.

195. Kitano H: Cancer as a robust system:implications for anticancer therapy. Nat Rev Cancer 2004, 4:227-235.

196. Miller WT: Tyrosine kinase signalling and the emergence of multicellularity. Biochim Biophys Acta 2012, 1823:1053-1057.

197. Suga H, Dacre M, de Mendoza A, Shalchian-Tabrizi K, Manning G, Ruiz-Trillo I: Genomic survey of premetazoans shows deep conservation of cytoplasmic tyrosine kinases and multiple radiations of receptor tyrosine kinases. Sci Signal 2012, 5:ra35.

198. Jadeau F, Grangeasse C, Shi L, Mijakovic I, Deleage G, Combet C: BYKdb: the Bacterial protein tYrosine Kinase database. Nucleic Acids Res 2012, 40:D321-D324.

199. Cozzone AJ: Bacterial tyrosine kinases: novel targets for antibacterial therapy? Trends Microbiol 2009, 17:536-543.

200. Gruenheid S, et al: Enteropathogenic E. coli Tir binds Nck to initiate actin pedestal formation in host cells. Nat Cell Biol 2001, 3:856-859.

201. Backert S, Tegtmeyer N, Selbach M: The Versatility of Helicobacter pylori CagA Effector Protein Functions: The Master Key Hypothesis. Helicobacter 2010, 15:163-176.

202. Selbach M, Paul FE, Brandt S, Guye P, Daumke O, Backert S, Dehio C, Mann M: Host cell interactome of tyrosine-phosphorylated bacterial proteins. Cell Host Microbe 2009, 5:397-403.

203. Blasutig IM, New LA, Thanabalasuriar A, Dayarathna TK, Goudreault M, Quaggin SE, Li SS, Gruenheid S, Jones N, Pawson T: Phosphorylated YDXV motifs and $\mathrm{Nck} \mathrm{SH2/SH3}$ adaptors act cooperatively to induce actin reorganization. Mol Cell Biol 2008, 28:2035-2046.
204. Frischknecht F, Moreau $V$, et al: Actin-based motility of vaccinia virus mimics receptor tyrosine kinase signalling. Nature 1999, 401:926-928.

205. Weisswange I, Newsome TP, Schleich S, Way M: The rate of N-WASP exchange limits the extent of ARP2/3-complex-dependent actin-based motility. Nature 2009, 458:87-91.

doi:10.1186/1478-811X-10-32

Cite this article as: Kaneko et al:: Phosphotyrosine recognition domains: the typical, the atypical and the versatile. Cell Communication and Signaling 2012 10:32.

\section{Submit your next manuscript to BioMed Central and take full advantage of:}

- Convenient online submission

- Thorough peer review

- No space constraints or color figure charges

- Immediate publication on acceptance

- Inclusion in PubMed, CAS, Scopus and Google Scholar

- Research which is freely available for redistribution

Submit your manuscript at www.biomedcentral.com/submit
( Biomed Central 